\title{
Revisão dos gêneros Sitalces, Eusitalces e Parasitalces (Orthoptera, Acrididae, Abracrini) e descrição de três novos gêneros
}

\author{
Maria Kátia Matiotti da Costa $^{1} \&$ Gervásio Silva Carvalho ${ }^{1}$
}

\author{
${ }^{1}$ Faculdade de Biociências, Laboratório de Entomologia, Prédio 12 D - sala 45 PUCRS. Av. Ipiranga, 6681. Caixa Postal 1429, 90619-900 \\ Porto Alegre-RS, Brasil. katiamatiotti@yahoo.com.br; gervasio@pucrs.br
}

\begin{abstract}
Revision of the genera Sitalces, Eusitalces and Parasitalces (Orthoptera, Acrididae, Abracrini) and description of three new genera. The South American Abracrini genera Sitalces Stål, 1878, Eusitalces Bruner, 1911, Parasitalces Bruner, 1911, Liebermannacris gen. nov., Robustusacris gen. nov., and Arimacris gen. nov. are reviewed, described, redescribed and redefined. Four species are new combinations: Liebermannacris dorsualis (Giglio-Tos, 1898) comb. nov., Liebermannacris punctifrons (Stål,1878) comb. nov., Arimacris trinitatis (Bruner, 1906) comb. nov., and Robustusacris balzapambae (Rehn, 1913) comb. nov., all removed of Sitalces Stål, 1878. Nine species are new synonymous: Sitalces robustus Bruner, 1908 (of S. volxemi Stål, 1878); S. infuscatus Bruner, 1908; S. nudus Bruner, 1908; S. ovatipennis Bruner, 1908; S. madeirensis Rehn, 1916 (of Liebermannacris dorsualis (Giglio-Tos, 1898); S. rubripes Hebard, 1924 (of Robustusacris balzapambae (Rehn, 1913); E. amazonicus Günther, 1940 and S. apolinari Hebard, 1923 (of Eusitalces vittatus Bruner, 1911); E. rubripes Günther, 1940 (of P. vulneratus (Bruner, 1919)). Lectotypes and paralectotypes are designated. Keys to identification of the genera and species, measurements, map of the geographical distribution and illustrations are added.
\end{abstract}

KEYWORDS. Eusitalces; Neotropical; Parasitalces; Sitalces; taxonomy.

RESUMO. Revisão dos gêneros Sitalces, Eusitalces e Parasitalces (Orthoptera, Acrididae, Abracrini) e descrição de três novos gêneros. Os gêneros sulamericanos de Abracrini Sitalces Stål, 1878, Eusitalces Bruner, 1911, Parasitalces Bruner, 1911, Liebermannacris gen. nov., Robustusacris gen. nov., e Arimacris gen. nov. são revisados, descritos, redescritos e redefinidos. Quatro espécies são novas combinações: Liebermannacris dorsualis (Giglio-Tos, 1898) comb. nov., Liebermannacris punctifrons (Stål,1878) comb. nov., Robustusacris balzapambae (Rehn, 1913) comb. nov., e Arimacris trinitatis (Bruner, 1906) comb. nov., todas removidas de Sitalces Stål, 1878. Nove espécies são novos sinônimos: Sitalces robustus Bruner, 1908 (de S. volxemi Stål, 1878); S. infuscatus Bruner, 1908, S. nudus Bruner, 1908, S. ovatipennis Bruner, 1908, S. madeirensis Rehn, 1916 (de Liebermannacris dorsualis (Giglio-Tos, 1898); S. rubripes Hebard, 1924 (de Robustusacris balzapambae (Rehn, 1913); E. amazonicus Günther, 1940 e S. apolinari Hebard, 1923 (de Eusitalces vittatus Bruner, 1911); E. rubripes Günther, 1940 (de P. vulneratus (Bruner,1919)). Lectótipos e paralectótipos são designados. São fornecidas chaves para identificação, medidas, mapa de distribuição geográfica e ilustrações dos gêneros e espécies.

PALAVRAS-CHAVE. Eusitalces; Neotropical; Parasitalces; Sitalces; taxonomia.

Sitalces Stål, 1878, Eusitalces Bruner, 1911 e Parasitalces Bruner, 1911 foram colocados por Amédégnato (1974) em Abracrini, Ommatolampinae, Acrididae.

Os Ommatolampinae constituem um grupo extremamente diversificado. A subfamília é constituída por 100 gêneros e aproximadamente 280 espécies (Cigliano \& Lange 1998). O mesonoto não visível, ou visível somente na região posterior, é a principal característica dos insetos incluídos nesta subfamília. Os espécimens desta subfamília são encontrados em habitat arborícola (Amédégnato \& Descamps 1980).

Abracrini foi proposta por Amédégnato (1974) e reúne, atualmente 16 gêneros e aproximadamente 90 espécies. A grande maioria das espécies da tribo está restrita à Região Neotropical e seus integrantes diferem das de outras por apresentar a apófise interna na genitália do macho ausente ou vestigial. São encontrados gafanhotos com o comprimento que varia entre 15 e $25 \mathrm{~cm}$, morfologicamente homogêneos, bastante atarracados, exceto espécies de raros gêneros com tendência longilínea, além da freqüencia de ao braquipterismo e micropterismo.

Sitalces foi descrito por Stål (1878: 16), na qual incluiu quatro espécies: S. vittiventris, S. punctifrons, $S$. coxalis e $S$. volxemi, esta designada como a espécie-tipo do gênero. As espécies deste gênero são usualmente associadas às plantas herbáceas encontradas nas margens de florestas (Bruner 1908). A distribuição geográfica de Sitalces corresponde à América do Sul. O gênero contém 18 espécies de tamanho médio (16 a $22 \mathrm{~mm}$ ), apresentando como característica principal às tégminas diminutas.

Eusitalces Bruner, 1911 foi descrito com base em $E$. vittatus um exemplar macho da Guiana, designada como espécie-tipo do gênero. $\mathrm{O}$ gênero é composto por quatro espécies, com indivíduos de tamanho médio (13 a $21 \mathrm{~mm}$ ), os quais apresentam tégminas curtas e cercos bifurcados. Eusitalces é exclusivamente Neotropical e distribui-se na Colômbia, Brasil, e Peru. Aparentemente Eusitalces lembra Sitalces Stål, 1878, mas se aproxima de Rhachicreagra Rehn, 1905 (Bruner, 1911).

Bruner, 1911, criou o gênero Parasitalces com uma única espécie, Parasitalces sexnotata do Brasil, Mato Grosso. Tamanho médio de (14 a $21 \mathrm{~mm}$ ).

Neste trabalho os gêneros Sitalces Stål, 1878, Eusitalces 
Bruner, 1911 e Parasitalces Bruner, 1911, foram revisados e redefinidos com o objetivo de contribuir para os estudos em Abracrini.

Por falta de material disponível no momento, as espécies Sitalces vittiventris Stål, 1878, S. coxalis Stål, 1878, S. varipennis Bruner, 1908, S. albipennis Bruner, 1910 e $S$. surinamensis Descamps \& Amédégnato, 1970, cujas características foram observadas no exame das fotografias dos exemplares-tipos, levam a crer que pertençam a um outro gênero, são excluídas do presente trabalho.

\section{MATERIAL E MÉTODOS}

Foram examinados 403 espécimes procedentes das seguintes coleções: Academy of Natural Sciences of Philadelphia, Pennsylvania, EUA (ANSP); Facultad de Ciencias, Universidad de la Republica, Montevideo, Uruguay (FCUR); Museu Nacional, Universidade Federal do Rio de Janeiro, Rio de Janeiro, RJ, Brasil (MNRJ); Museu de Zoologia, Universidade de São Paulo, São Paulo, SP, Brasil (MZSP); Museo de La Plata, Division Entomologia, Universidad Nacional de La Plata, La Plata, Argentina (MLPA); Museo Instituto di Zoologia ed Anatomia Comparata, Universitá di Torino, Turin, Itália (MIZT); Instituto Nacional de Pesquisas da Amazônia, Manaus, AM, Brasil (INPA); Naturhistoriska Riksmusset, Stockholm, Suécia (NHRS); Museo Nacional de Ciencias Naturales, Espanha, Madrid (MNMS).

Para identificação das espécies buscou-se, prioritariamente, a sua comparação com os tipos; quando não foi possível, recorreu-se ao material comparado com os mesmos e fotografias do material-tipo feitas pelo Prof. Carlos Salvador Carbonell da Facultad de Ciencias, Universidad de la Republica, Montevideu, Uruguay (FCUR), ou ainda à descrição original.

Os dados do material examinado são apresentados conforme encontrados nas etiquetas. Seguiram-se as recomendações de Papavero \& Martins (1994). Na distribuição geográfica, além dos dados das etiquetas, são acrescentadas informações da bibliografia.

As mensurações dos exemplares examinados foram realizadas utilizando um paquímetro digital (Starrett) e, sempre que necessário, o auxílio de microscópio estereoscópico com ocular micrométrica. As medidas, dadas em milímetros, correspondem à média de, no máximo 20 , exemplares (10 machos e 10 fêmeas) ou entre os espécimes disponíveis. As abreviações empregadas, e seus significados são as seguintes: C.c., comprimento total do corpo; C.t., comprimento da tégmina, tomado da base até o final da mesma; C.p., comprimento do pronoto; C.f., comprimento do fêmur posterior.

As ilustrações foram realizadas com o auxílio de câmara clara acoplada ao microscópio estereoscópico. Machos de todas as espécies foram ilustrados pela primeira vez. Foram ilustradas, também, a genitália externa de ambos os sexos.

A nomenclatura da morfologia interna e das peças da genitália segue-se Dirsh (1956) e Amédégnato (1976).

\section{RESULTADOS E DISCUSSÃO}

Chave para os gêneros de Abracrini

1. Carena mediana do pronoto não proeminente; pronoto não tectiforme; ápice das tégminas pontiagudo. Placa supranal subretangular, com projeção mediana em forma de Y; cercos longos e delgados; com fúrcula no último tergo do abdome. Edeago longo e robusto

Sitalces Stål

Carena mediana do pronoto proeminente; pronoto tectiforme; ápice das tégminas arredondado. Placa supranal subtriangular, sem tal projeção mediana; cercos curtos e cônicos; sem fúrcula no último tergito do abdome. Edeago curto e estreito ......................... 2

2. Tegumento rugoso-tuberculado. Occipício arqueado, com um par de sulcos; . costa frontal sulcada; carena e carênula interna dos fêmures posteriores serreadas, com uma mancha escura na superfície dorso-external Robustusacris gen. nov.

Tegumento rugoso-puncturado. Occipício plano, sem sulcos; costa frontal plana; carena e carênula interna dos fêmures posteriores não serreadas, sem mancha escura na superfície dorso external .. 3

3. Epífalo com ponte convexa; projeções anteriores maiores do que as âncoras; lophi do epífalo não esclerotizados; edeago curto .................... Liebermannacris gen. nov.

Epífalo com ponte plana; projeções anteriores do mesmo tamanho que as âncoras; lophi do epífalo esclerotizados; edeago longo

.. 4

4. Duas saliências na porção mediana da placa supranal. Segmentos abdominais 2-5 com amplas manchas laterais pretas. Cercos não bifurcados; pálio saliente Arimacris gen. nov.

Sem saliências na porção mediana da placa supranal. Segmentos abdominais 2-5 sem manchas laterais. Cercos bifurcados; pálio não saliente .................... 5

5. Bifurcação dos cercos angulada. Placa supranal subtriangular; sem fúrcula no último tergito. Cercos com haste externa mais longa do que a interna. Edeago curto e estreito; bainha ectofálica estreita

Eusitalces Bruner

Bifurcação dos cercos arredondada. Placa supranal subretangular; com fúrcula no último tergito. Cercos com haste externa do mesmo tamanho do que a interna. Edeago longo e robusto; bainha ectofálica ampla; Micrópteros ou ápteros Parasitalces Bruner 


\section{Sitalces Stål, 1878}

Sitalces Stål, 1878: 16; Brunner Von Wattenwyl 1893: 139; Giglio-Tos, 1898: 48 (chave), Bruner, 1908 (1900-09): 291 (chave para espécies); Kirby 1910: 434 (designação da espécie-tipo); Rehn, 1913: 105; Descamps \& Amédégnato, 1970: 890 (lista de 7 espécies); Amédégnato, 1974: 202 (Ommatolampinae, Abracrini)

Espécie-tipo: Sitalces volxemi Stål, 1878, designação subseqüente por Kirby, 1910: 434.

Diagnose. Micrópteros, com coloração castanhoferruginosa; antenas filiformes com 18 artículos. Tegumento puncturado; pronoto não tectiforme, com carena mediana visível, mas não proeminente; ápices das tégminas pontiagudo; placa supranal subretangular, margens laterais e mediana arredondadas com projeção longitudinal mediana profunda em forma de Y; placa subgenital curta, ápice em processo curto; cercos longos e delgados, apenas o terceiro basal espesso; borda posterior do último tergito com uma pequena fúrcula.

Sitalces volxemi Stål, 1878

(Figs. 1A, 1B, 1C, 1D, 1E, 1F, 1G)

Sitalces volxemi Stål, 1878: 16; Kirby, 1910: 435; Rehn, 1917: 349 (Brasil, RJ, Petrópolis); Sjöstedt, 1933: 37 (locação dos tipos); Ferreira et al. 1980: 91 (cromossomos); Mesa et al. 1983: 522 (cromossomos).

Sitalces robustus Bruner, 1908: 291 (chave); Bruner, 1911: 122 (redescrição); Kirby, 1910: 435; Liebermann, 1955: 342; Otte, 1978: 33. Syn. nov.

Macho (Fig. 1A). Tegumento puncturado. Coloração castanho-ferruginosa, dorsalmente mais clara, lateralmente mais escuro. Medidas (em mm), respectivamente 6 Machos/ 5 Fêmeas: C.t., 15,7 (16,0-16,6)/ 20,7 (18,8-22,9); C. p., 3,5 $(3,6-3,8) / 4,1(3,5-4,8)$; C. f., $10,1(9,4-11,1) / 12,1(12,6-13,5)$; C. t., $1,7(1,6-1,9) / 1,4(1,2-1,8)$.

Cabeça. De perfil, face subretilínea; cabeça um pouco mais larga que a parte anterior do pronoto; costa frontal puncturada, plana e não proeminente aos ocelos; ocelo mediano pequeno, pouco visível; abaixo deste as carenas que o delimitantes laterais com extremidades arredondadas; ocelos laterais fortemente convexos e proeminentes; carenas frontais bem marcadas; fronte e genas manchadas de amarelo; fastígio do vértice plano, um pouco mais largo do que longo, arredondado no ápice e limitado levemente por uma carena elevada; sulco fastigial rugoso e puncturado; espaço interocular estreito; olhos grandes e proeminentes, sem espaço entre o olho e a margem lateral da cabeça (Fig.1B). Faixa amarelada com origem próxima do olho e estendida até à metade inferior dos lóbulos laterais do pronoto; antenas filiformes, castanho-claras, um pouco mais longas do que a cabeça e pronoto juntos, com escapo grande, pedicelo pequeno, flagelo cilíndrico constituído de 18 artículos, os basais com separação indistinta.

Tórax. Pronoto puncturado, com carena mediana visível, mas não proeminente cortada por três sulcos transversais, sendo o último mais profundo; prozona maior que a metazona; duas regiões da prozona sem puncturas; ausência de carenas laterais; borda posterior do pronoto não angulada, com uma reentrância na região mediana (Fig. 1B), lóbulos laterais sinuosos. Tubérculo prosternal piramidal, com uma pequena proeminência espiniforme no centro; espaço mesosternal largo, subquadrado e lóbulos metasternais estreitos, subcontínuos. Pernas anteriores e medianas muito robustas; fêmur posterior robusto, amarelo-esverdeado, alcançando a extremidade do abdome; carena superior puncturada e imaculada; pleura e inserção do fêmur posterior manchada de amarelo; lúnula genicular ferruginosa, tíbia posterior robusta, esverdeada, com base ferruginosa, hirsuta, 8 espinhos externos com extremidades pretas, sem espinho apical; 9-10 espinhos internos, o apical muito grande; Tégminas de coloração ferruginosa, escamiformes, tão largas quanto longas, alcançando somente a borda posterior do metanoto, ápice levemente pontiagudo.

Abdome. Tímpano inconspícuo; placa supranal subretangular, mais larga do que longa, margens laterais e mediana arredondadas com projeção longitudinal mediana profunda em forma de Y, com a parte anterior chanfrada e a posterior acuminada, em relação aos cercos mais curta (Fig.1C); placa subgenital curta, ápice em processo curto e truncado, voltado para cima; cerco longo, delgado, estreito, apenas o terceiro basal espesso (Fig. 1D); borda posterior do último tergito com uma pequena fúrcula. Últimos segmentos abdominais, dorsalmente, com pares de manchas brancas, exceto o último.

Complexo fálico. Cíngulo com apódema bem desenvolvido, longa; escleritos endofálicos com ápodema achatado dorso-ventralmente, placas laterais expandidas lateralmente; bainha ectofálica ampla, englobando mais da metade do esclerito inferior do edeago; gonóporo com expansão ventral retangular; edeago com valvas superior e inferior longas e de mesmo tamanho, com ápices divididos (Fig. 1F). Epífalo com ponte ampla e plana, projeções anteriores desenvolvidas, mais curtas que as âncoras, estas curvadas com ápices agudos e convergentes, projeções posteriores proeminentes, lophi não curvados com protuberância mediana proeminente; presença de escleritos ovais (Fig. 1G).

Fêmea. Similar ao macho, porém maior (comprimento $20,7 \mathrm{~mm}$ ) e mais robusta. Olhos menos proeminentes, ocelos laterais menores e menos convexos; margem posterior das tégminas apenas alcançando a metade do metanoto. Valvas do ovipositor longas, margem superior da valva dorsal levemente serreada, o ápice dorsal moderadamente curvado, dente apical externo da valva ventral levemente proeminente (Fig. 1E). Caracteres cromáticos coincidentes com os descritos para o macho.

Material examinado. Lectótipo macho aqui designado: "Sitalces volxemi 

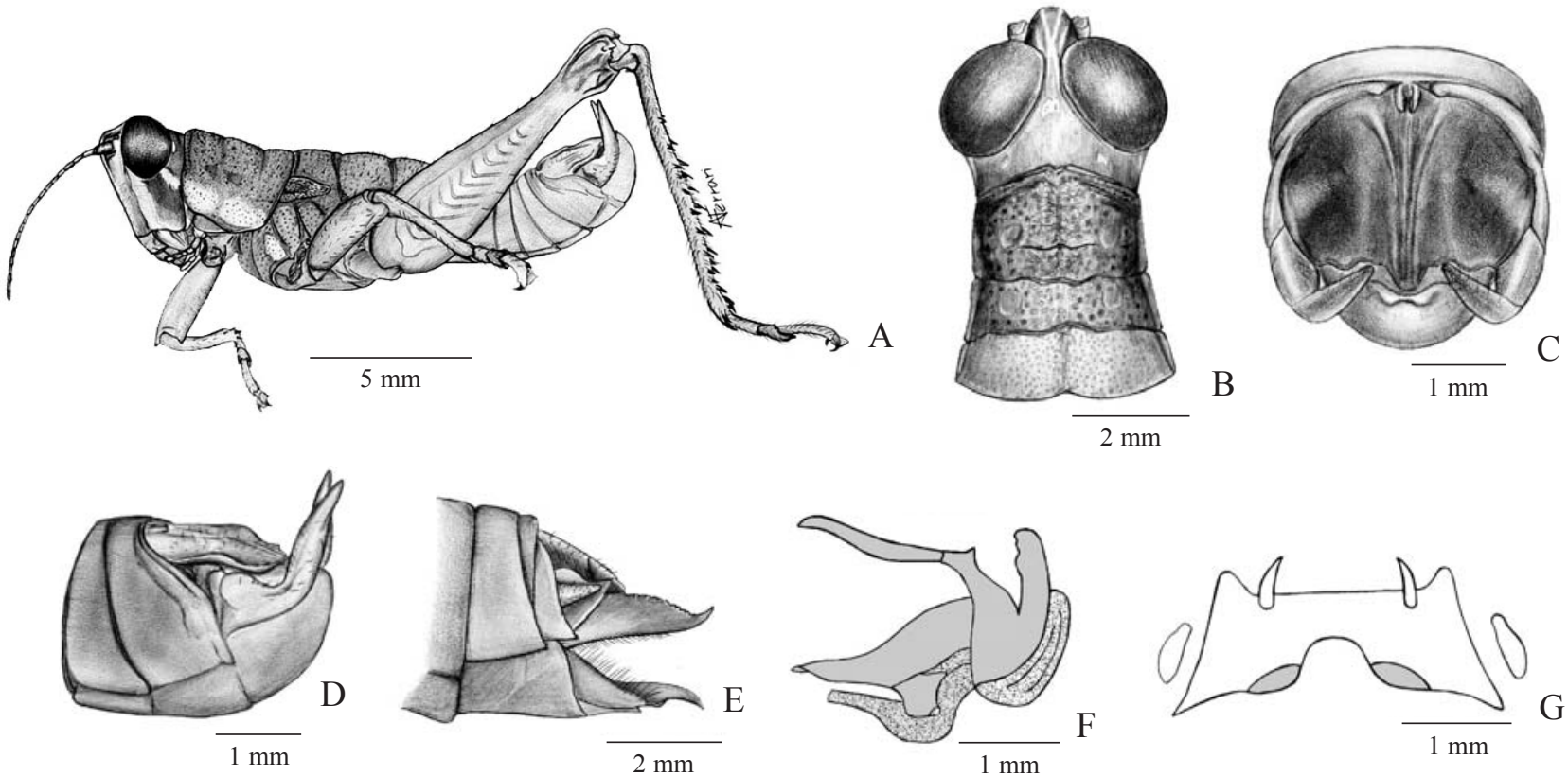

Figs. 1A, Sitalces volxemi Stål, 1878, macho; B, Cabeça e protórax, vista dorsal; C, Extremidade abdominal, vista dorsal; D, mesma, vista lateral; E, Valvas do ovipositor da fêmea, vista lateral; F, Complexo fálico com epífalo removido, vista lateral. G, Epífalo, vista dorsal.

Stål, det. Stål”, "Coll. Camille van Volxem", "Typus", sem etiqueta de procedência, genitália dissecada por "CSC 1080" (NHRS). Paralectótipo fêmea aqui designado: "Sitalces volxemi Stål, det. Stål," "Coll. Br. V. W., Boucard, det." Etiqueta "8988" (NHMW). BRASIL. Rio de Janeiro: Guanabara, Sernambetiba, 4.xi.1961 (A. Mesa), 3 machos e 10 fêmeas (FCUR; C. S. Carbonell det. 1975); Represa do Rio Grande, 26.iii.1966 (F. M. Oliveira), 2 machos e 1 fêmea (MNRJ); idem, iii.1966 (F. M. Oliveira), 1 macho (MZSP; C. S. Carbonell det. 1980); idem, 18.vi.1977 (B. Silva), 1 fêmea (MNRJ); idem, ii.1978 (B. Silva), 1 macho (MNRJ); Muri, 4.ii.1977 (Seabra, Roppa \& Monné), 1 macho (MNRJ); Boca do Mato, 26.v.1977 (B. Silva), 1 fêmea (MNRJ); Parque Nacional Itatiaia, 26.x.1964 (P. R. San-Martin \& M. A. Monné), 1 macho e 2 fêmeas (FCUR; comparado com o tipo/ S. robustus/ C. S. Carbonell det. 1980); idem, 30.i.1966 (P. R. SanMartin \& M. A. Monné), 1 fêmea (FCUR; comparado com o tipo /S robustus/ C. S. Carbonell det. 1980); Espírito Santo: Vitória, s.d. (L. Bruner), 1 macho e 1 fêmea (MLPA)

Distribuição geográfica. Brasil (Rio de Janeiro, Espírito Santo) (Fig. 9).

Notas sobre os tipos. Exame somente de fotografias; lectótipo macho em ótimo estado; paralectótipo fêmea de $S$. volxemi depositado no NHMW, sem o par de antenas e a perna anterior esquerda.

Comentários. Ao comparar as fotografias do material tipo depositado no NHRS e NHMW, e os exemplares, assim como o exame das genitálias externa e interna, estabeleceu-se que as espécies $S$. volxemi Stål, 1878 e $S$. robustus Bruner, 1911 correspondem a uma única espécie.

\section{Liebermannacris gen. nov.}

Espécie-tipo: Ommatolampis dorsualis Giglio-Tos, 1898.

Diagnose. Micrópteros; antenas filiformes 17-18 artículos.
Coloração castanho-escura para preto até o $5^{\circ}$ segmento abdominal, exibindo duas listras occipitais, duas pronotais laterais, e uma médio-dorsal, amareladas. Tegumento rugosopuncturado; occipício plano, com ou sem puncturas; placa supranal subtriangular alongada, mais longa do que larga, com bordas laterais elevadas, grossas e convergentes, com uma carena transversal e sulco longitudinal mediano; placa subgenital curta; cercos longos e delgados, um pouco mais longos do que placa supranal, curvados para dentro na metade distal.

Etimologia. Nome dado em homenagem ao pesquisador Dr. José Liebermann (in memorian) por sua contribuição sistemática e coletas de acridóideos em toda América do Sul; Liebermann + akris (= gafanhoto).

Chave para as espécies de Liebermannacris

1. Tegumento do corpo levemente rugoso-puncturado; occipício sem puncturas; prozona com puncturas menos profundas, dispostas igualmente em relação as presentes na metazona; fastígio do vértice com ápice levemente arredondado; tíbia posterior com 6 espinhos na margem externa; extremidade posterior do último segmento abdominal com incisão na porção mediana; valvas do ovipositor robustas

Liebermannacris dorsualis (Giglio-Tos)

Tegumento do corpo profundamente rugoso-puncturado; occipício com puncturas; prozona com puncturas mais profundas, dispostas esparsamente em relação as presentes na metazona; fastígio do vértice com ápice extremamente arredondado; tíbia posterior com 7 espinhos na margem externa; extremidade posterior do último segmento abdominal sem incisão na porção 

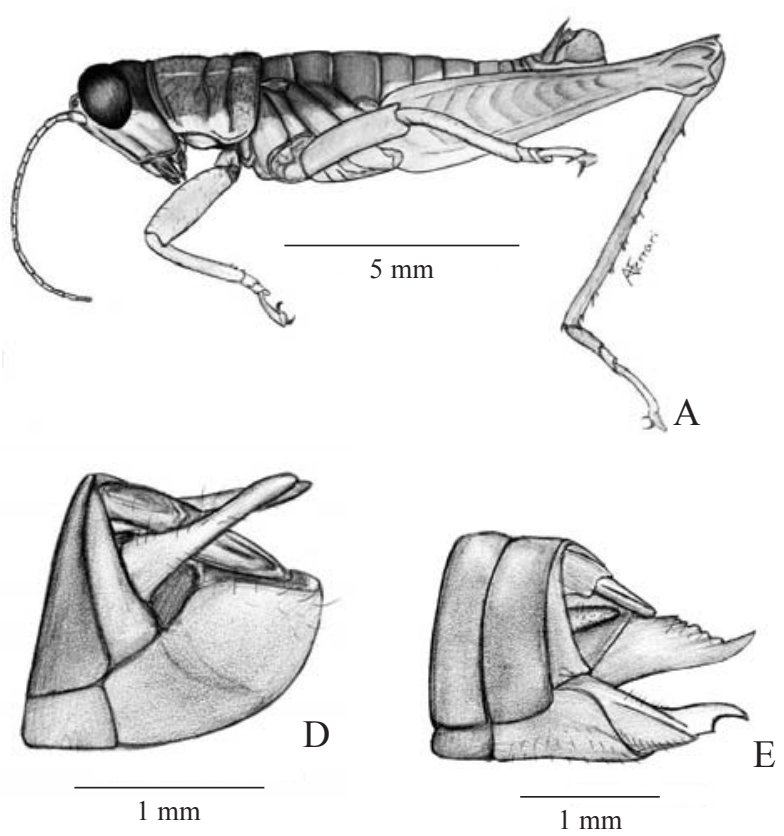
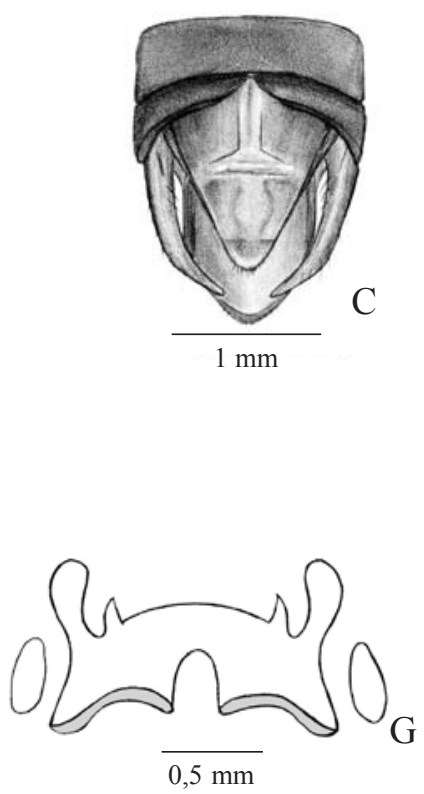

Figs. 2A, Liebermannacris dorsualis (Giglio-Tos,1898) macho; B, Cabeça e protórax, vista dorsal; C, Extremidade abdominal, vista dorsal; D, mesma, vista lateral; E, Valvas do ovipositor da fêmea, vista lateral; F, Complexo fálico com epífalo removido, vista lateral; G, Epífalo, vista dorsal.

mediana; valvas do ovipositor delgadas .....

Liebermannacris punctifrons (Stål)

Liebermannacris dorsualis (Giglio-Tos, 1898) comb. nov. (Figs. 2A, 2B, 2C, 2D, 2E, 2F, 2G)

Ommatolampis dorsualis Giglio-Tos, 1898: 66. Kirby, 1910: 434; Passerin, 1981: 45.

Sitalces dorsualis (Giglio-Tos, 1898): 2. Carbonell \& Descamps, 1978: 2; Mesa et al. 1983: 521 (cromossomos).

Sitalces infuscatus Bruner, 1908: 291. (chave) Bruner, 1911: 123 (redescrição), 1913: 492; Kirby, 1910: 435; Liebermann, 1955: 342; Descamps, 1976: 301 (ecologia); Mesa et al. 1983: 521 (cromossomos); Otte, 1978: 33 (localização do tipo). Syn. nov.

Sitalces nudus Bruner, 1908: 291 (chave), 1910: 486; Kirby, 1910: 435; Liebermann, 1955: 342, 1963: 64; Otte, 1978: 33 (localização do tipo). Syn. nov.

Sitalces ovatipennis Bruner, 1908: 292. Grossbeck, 1912: 357; Rehn, 1918:185; Descamps \& Amédégnato, 1970: 891; Descamps, 1979: 313. Syn. nov.

Sitalces madeirensis Rehn, 1916: 300. Liebermann, 1955: 342; Otte, 1978 : 59 (locação do tipo). C. S. Carbonell (com. pes.) Syn. nov.

Macho (Fig. 2A). Tegumento levemente rugosopuncturado. Coloração da superfície dorsal da cabeça, tórax, e base do abdome castanho-escura para preto até o $5^{\circ}$ segmento abdominal, exibindo duas listras occipitais, duas pronotais laterais, e listra médio-dorsal, amareladas, que estendidas desde o pronoto até à metade do abdome. Corpo moderadamente hirsuto, pronoto, tórax e o primeiro segmento abdominal, puncturado e o resto das porções do corpo lisos. Medidas em (mm), respectivamente 10 machos / 10 fêmeas: C. c., $11,9(11,1-13,0) / 15,3(14,9-18,6)$; C. p., $2,5(2,1-3,1) /$ 4,1 (2,5-4,0); C.f., 7,8 (7,1-8,4)/ 12,1 (8,4-10,4); C.t.,1,0/ 1,0.
Cabeça. De perfil face oblíqua, face margeada por uma carena bem marcada; cabeça mais larga que a margem anterior do pronoto; costa frontal não proeminente sobre os ocelos, plana, com algumas puncturas profundas na sua extremidade posterior; fastígio do vértice subtriangular, estreito, longitudinalmente sulcado, ligeiramente mais largo que longo com o ápice levemente arredondado; espaço interocular estreito; olhos grandes e proeminentes, sem espaço entre o olho e a margem lateral da cabeça, espaço interocular estreito (Fig. 2B); antenas filiformes mais longas do que a cabeça e pronoto juntos, composta por 18 artículos.

Tórax. Pronoto subcilíndrico, grosseiramente puncturado, carena mediana distinta, mas não proeminente cortada por três sulcos transversais profundos, ausência de carenas laterais; prozona com duas regiões sem puncturas; metazona menor em tamanho em relação a prozona e bastante puncturada, borda posterior do pronoto não angulada, com uma reentrância na região mediana (Fig. 2B). Dorso do meso e metatórax, juntos com o primeiro segmento abdominal, grosseiramente puncturado; Tubérculo prosternal piramidal com o ápice acuminado; espaço mesosternal subquadrado e lóbulos metasternais próximos; pernas esverdeadas, fêmur posterior ultrapassando a extremidade do abdome, carena superior com minúsculos espinhos, lúnula genicular avermelhada; tíbia posterior hirsuta com 6 espinhos na margem externa, e 8 na interna com ápices pretos, base da tíbia ferruginosa; tégminas escamiformes, escassamente alcançando a metade da metanoto, coloração preta com metade superior amarelada. 

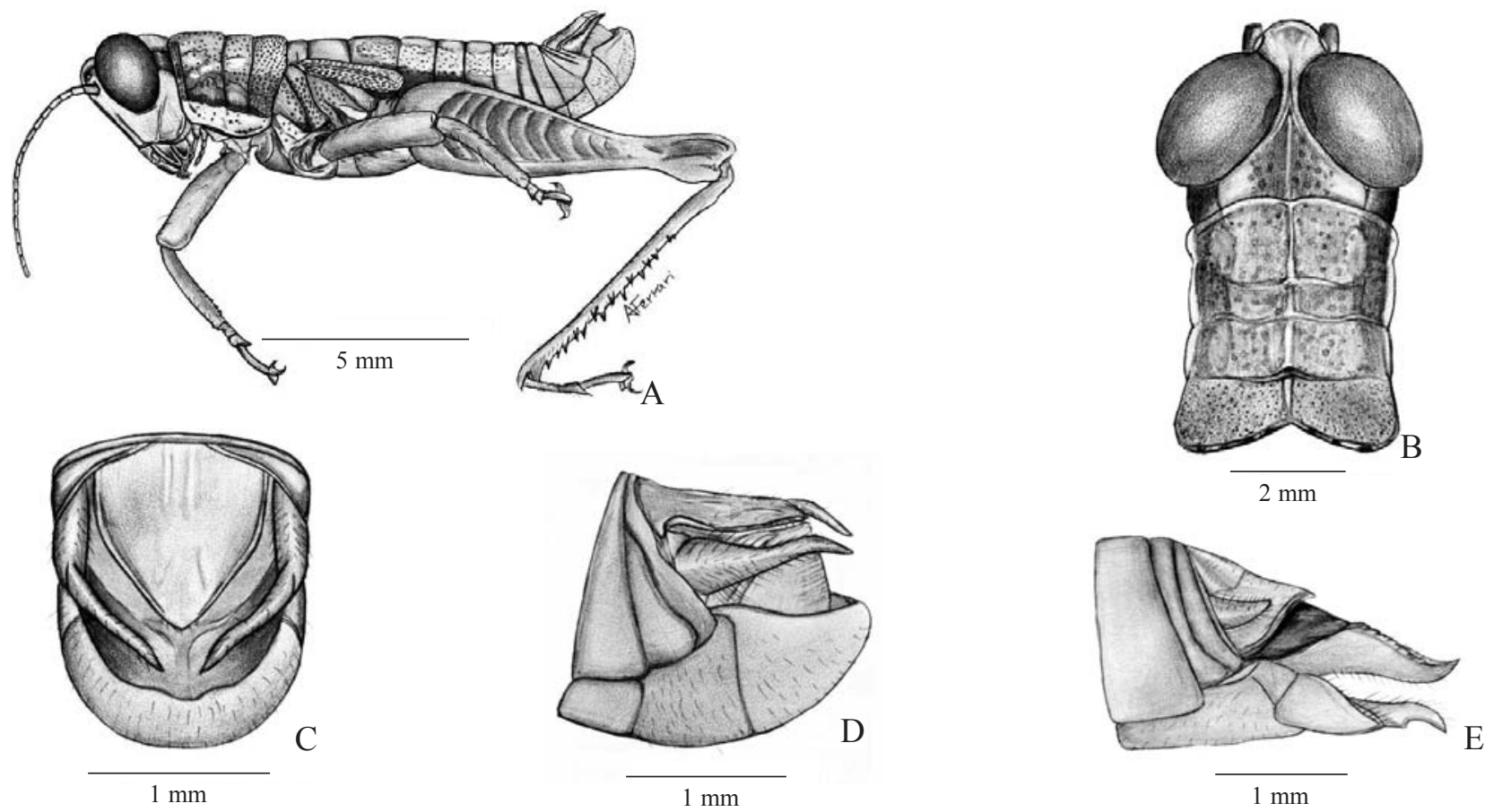

Figs. 3A, Liebermannacris punctifrons (Stål, 1878), macho; B, Cabeça e protórax, vista dorsal. C, Extremidade abdominal, vista dorsal; D, mesma, vista lateral; E, Valvas do ovipositor da fêmea, vista lateral.

Abdome. Tímpano pequeno; placa supranal subtriangular alongada, mais longa do que larga, com bordas elevadas e grossas, cruzada até a metade por uma carena transversal, na metade distal suavemente curvada para baixo (Fig. 2C); placa subgenital curta e obtusa; cercos longos, delgados, um pouco mais longos do que a placa supranal, curvados para dentro na metade distal (Fig. 2D). Superfície ventral do abdome amarelada.

Complexo fálico. Apódema do cíngulo bem desenvolvida e longa; escleritos endofálicos achatados dorso-ventralmente; gonóporo com expansão ventral retangular; edeago curto com valvas superior e inferior do mesmo tamanho, com ápices divididos; bainha ectofálica do edeago ampla (Fig. 2F). Epífalo com ponte ampla, levemente convexa, âncoras curvadas com ápices agudos e convergentes, mais curtas que as projeções anteriores, sendo estas muito desenvolvidas, mais longas que as âncoras, lophi curvados, protuberância mediana proeminente; escleritos ovais bem desenvolvidos (Fig. 2G).

Fêmea. Similar ao macho, porém maior (comprimento 18 $\mathrm{mm}$ ), e mais robusta; olhos menos proeminentes; antenas filiformes, comprimento menor do que a cabeça e pronoto juntos; dorso do meso e metatórax, junto com o primeiro segmento abdominal; cercos curtos e cônicos; valvas do ovipositor robustas, margem superior da valva dorsal serreada com ápice levemente curvado, dente apical externo da valva ventral lisa e proeminente (Fig. 2E). Caracteres cromáticos coincidentes com os descritos para o macho.

Material examinado. Lectótipo macho aqui designado: "Sitalces ovatipennis Bruner Type" "Demerara, British Guiana, S. A., 1901" (UNSM) Paralectótipos aqui designados: "Sitalces ovatipennis Bruner": 10 machos e 11 fêmeas: Demerara (R. J. Crew, coleção de L. Bruner), Bártica (J. A. G. Rehn, coleção da Acad. Nat. Sci. Philad.). GUIANA. Berbice-Corentyne: Bártica, 25.v.1901 (Rehn Col.), 1 macho (ANSP; Cotype Bruner). BRASIL. Roraima: Ilha de Maracá, vi.1981 (sem coletor) 1 macho e 1 fêmea (INPA; 0022058 macho; 0022378 fêmea/ M. Descamps det.1981/ Museum ParisBrésil); Pará: Belém, 10.vi. 1966 (Pablo R. San Martin); Óbidos, 10.ix.1919 (H. S. Parish), 1 macho (ANSP; parátipo/ Sitalces nudus); Amazonas: Benjamin Constant, viii.1977 (B. Silva), 1 macho (MNRJ/ C. S. C. det. 1978); Humaitá, 8.x.1975 (A. Mesa), 6 machos e 2 fêmeas (FCUR); Tabatinga, x.1977 (B. Silva), 1 macho (MNRJ); Manaus, Cohabam, Japiim II, 30.v.76 (Dellome), 1 macho e 1 fêmea (INPA; 0022607-8) Mn. Am. Br/ S. ovatipennis/ Vieira, M.F. det. 1997); Mato Grosso: Chapada dos Guimarães, iii.1979 (Roppa \& Silva), 1 macho (MNRJ); Juiná, v. 1985 (O Roppa \& B. Silva), 1 fêmea (MNRJ); BR 163 Km, viii. 1978 (Monné \& Roppa), 1 macho (MNRJ; S. infuscatus/ M. A. Monné det. 1979); Itaum, iii. 1974 (Moacir Alvarenga), 1 fêmea (MLPA; S. ovatipennis); São Paulo: Piracicaba, Paredão Vermelho, 23.v.1962 (A. Mesa), 1 fêmea (FCUR); Rio de Janeiro: Sierra do Fazadão, 28.xi.1961 (A. Mesa), 1 macho (FCUR; $S$. infuscatus/ C. S. C. det. 1966/ comparado com o tipo); Paraná: Serra do Mar, v.1964 (F. Plaumann) 1 fêmea (MLPA; S. ovatipennis); EQUADOR. Valle del Santiago, s.d, (sem coletor), 1 macho e 1 fêmea (FCUR; parátipos de Giglio-Tos/ Ommatolampis dorsualis). PERU. Loreto: Iquitos, 8.ii.1962 (A. Mesa), 1 macho (FCUR); Tamshiyacu, Rio Amazonas, 10.ii.1962 (A. Mesa), 1 macho e 2 fêmeas (FCUR); San Jorge, Pucallpa, 19.ii.1962 (A Mesa), 2 fêmeas (FCUR); Huánuco: Aucayacu, 4.ii.1962 (A. Mesa), 7 machos e 10 fêmeas (FCUR); Atalaya, confluência rios Alto Madre de Dios y Carbón, vi.1976 (C.S. Carbonell \& M. Descamps), 15 machos e 11 fêmeas (FCUR); Madre de Dios: Boca del rio Pinquin en rio Manu, vi. 1976 (M. Descamps \& C.S. Carbonell), 2 machos e 1 fêmea (FCUR); Pakitza, rio Manu, vi. 1976 (C.S. Carbonell \& M. Descamps), 18 machos e 21 fêmeas (FCUR); Cuzco: Paucartambo, Pilcopata, vi.1976 (M. Descamps \& C.S. Carbonell), 4 machos e 2 fêmeas (FCUR); Machu Picchu, 1-2.vii.1964 (B. Malkin), 5 machos (MZSP); La Convención, Quiteni, 10.vi.1976 (M. Descamps \& C.S. Carbonell), 1 fêmea (FCUR). BOLÍVIA. Cochabamba: Vila Tunari, 7.i.1958 (sem coletor), 1 fêmea (MLPA; S. infuscatus); La Paz: Coroico, 26.ii.1956 (Monros), 1 macho (MLPA; S. infuscatus). 

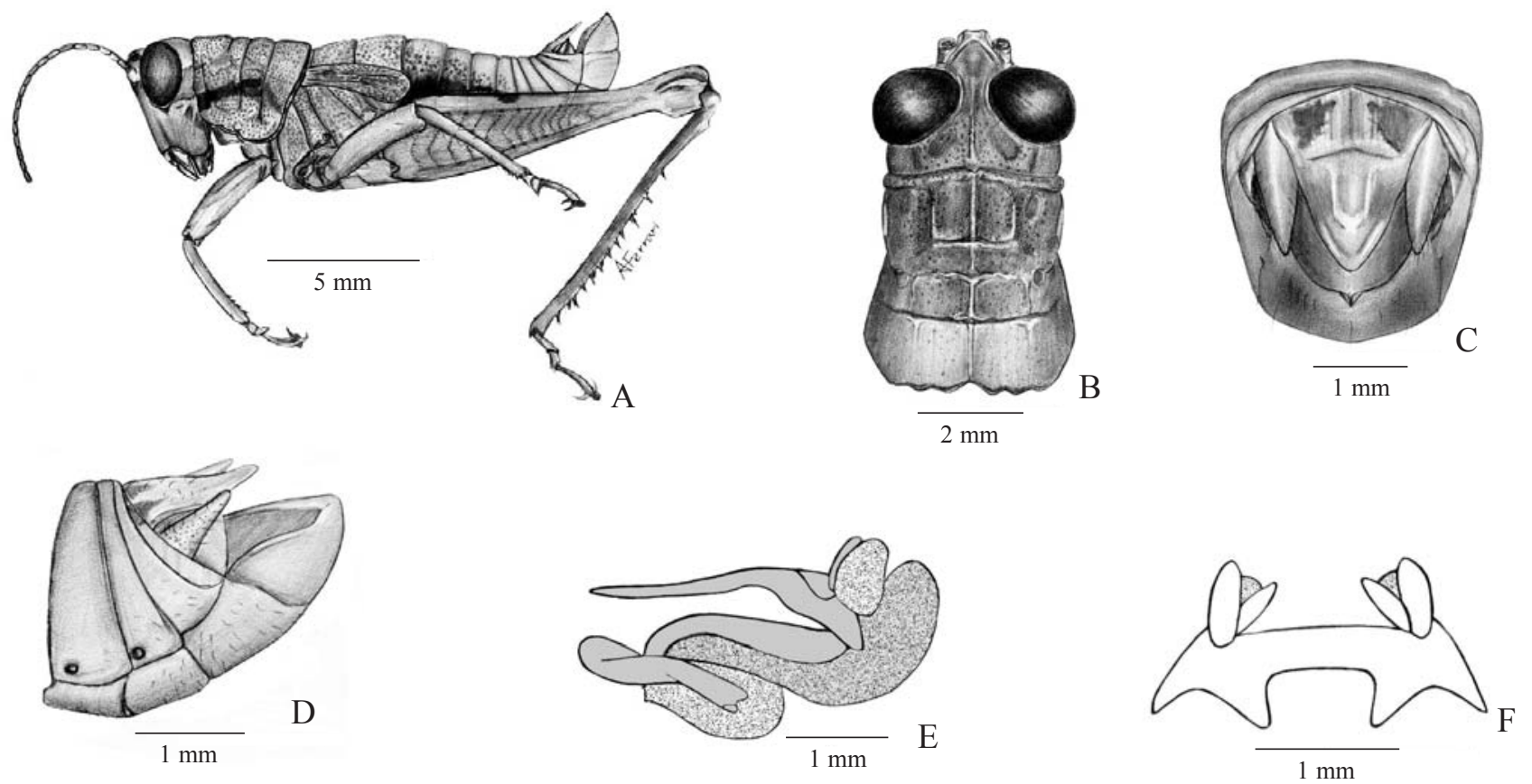

Figs. 4A, Robustusacris balzapambae (Rehn, 1913), macho; B, Cabeça e protórax, vista dorsal; C, Extremidade abdominal, vista dorsal; D, mesma, lateral; E, Complexo fálico com epífalo removido, vista lateral. F, Epífalo, vista dorsal.

PARAGUAI. Alto Paraná: Puerto Presidente Franco, 15.iii.1965 (C.S. Carbonell, A. Mesa \& M. A. Monné), 4 machos e 6 fêmeas (FCUR; Sitalces infuscatus/ C. S. Carbonell det. 1966); idem, 1 macho (ANSP; Sitalces nudus); 50 km. W. do rio Paraná, 14.iii.1965 (C. S. Carbonell, A. Mesa \& M. A. Monné), 2 machos e 2 fêmeas (FCUR); Caaguazú: 12.iii.1965 (C. S. Carbonell, A. Mesa \& M. A. Monné), 1 fêmea (FCUR); Ruta Caaguazú-lhú, 40 km N. de Caaguazú, 13.iii.1965 (C. S. Carbonell, A. Mesa \& M. A. Monné), 1 fêmea (FCUR); Paraguarí: Sapucay, 7.iii.1965 (C. S. Carbonell, A. Mesa \& M. A. Monné), 1 macho (FCUR); Paraguarí, 10.iii.1965 (C. S. Carbonell, A. Mesa \& M. A. Monné), 1 fêmea (FCUR). ARGENTINA. Misiones: Rio Paranay-Guazú, 17.iii.1965 (C.S. Carbonell, A. Mesa \& M. A. Monné), 1 fêmea (FCUR).

Notas sobre os tipos. Parátipos de O. dorsualis, $S$. nudus e lectótipo macho de $S$. ovatipennis em ótimo estado para exame.

Comentários. A série-tipo de $S$. ovatipennis é composta por 11 machos e 11 fêmeas (Bruner, 1908), distribuídos nas seguintes coleções: ANSP (16 exemplares); no AMNH (2) e na UNSM (4). O exemplar pertencente à série-tipo com procedência de Bártica (J. A. G. Rehn, coleção Acad. Nat. Sci. Philad.) foi examinado pelos autores.

A espécie aproxima-se de L. punctifrons, diferindo desta, pela disposição e profundidade das puncturas presentes, principalmente, no pronoto; número de espinhos na margem externa da tíbia posterior e presença de curvatura na metade distal da placa supranal.

Os machos de L. dorsualis provenientes do Peru, Departamento de Cuzco (Atalaya e Machu-Picchu), não apresentam as listras occipitais, pronotais laterais e a medianodorsais amareladas. Tégminas apresentam-se de coloração preta em ambos os sexos.

Os exemplares machos provenientes do Departamento de Huánuco (Aucayacu), região centro-oeste do Peru, apresentam as listras occipitais, pronotais laterais e a mediana dorsal amareladas pouco visíveis, porém, apresentam uma mancha avermelhada na parte distal do fêmur posterior, ausente nos demais exemplares do Peru.

O exemplar macho proveniente de Manaus (Cohaban), apresenta as antenas avermelhadas desde o pedicelo.

Através do exame dos tipos e uma série extensiva de exemplares comparados com os mesmos, procedentes de Guiana, Brasil, Equador, Peru, Paraguai e Argentina, estabeleceu-se que S. infuscatus Bruner, 1908, S. nudus Bruner, 1908, S. ovatipennis Bruner, 1908 e S. madeirensis Rehn, 1916, são sinônimos de L. dorsualis.

Distribuição geográfica. Guiana (Bártica); Brasil (Pará, Amazonas, Roraima, Rondônia, Mato Grosso e Rio de Janeiro; Argentina (Misiones); Equador (Morona-Santiago); Peru (Loreto, Huánuco, Junin, Cuzco e Madre de Dios; Paraguai (Alto Paraná, Paraguarí e Caaguazú); e Bolívia (Cochabamba e La Paz) (Fig. 9).

Liebermannacris punctifrons (Stål, 1878) comb. nov. (Figs. 3A, 3B, 3C, 3D, 3E)

Sitalces punctifrons Stål, 1878: 18; Bruner, 1908 (1900-09): 292; Kirby, 1910: 435; Roberts, 1937: 356; Sjösted, 1933: 63 (locação do tipo).

Macho (Fig. 3A). Tegumento profundamente rugosopuncturado. Coloração castanho-escura, superfície ventral mais clara. Medidas em (mm), respectivamente 1 macho e 1 fêmea: C.c., 13,03/ 19,9; C.p., 3,07/ 4,07; C. f., 7,9/ 9,6; C.t., 3,2/ 2,7.

Cabeça. De perfil face oblíqua; cabeça mais larga do que a margem anterior do pronoto; costa frontal plana, não 

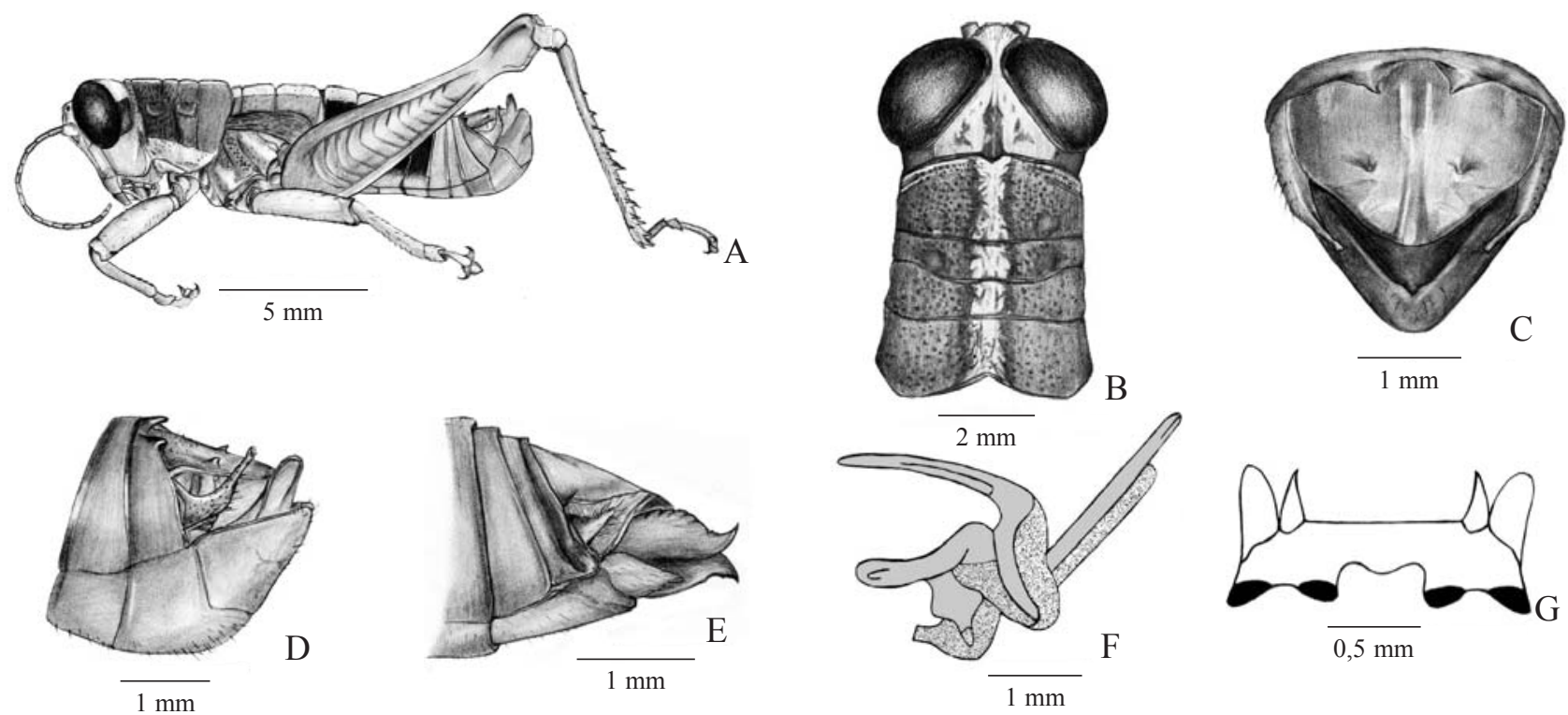

Figs. 5A, Arimacris trinitatis (Bruner, 1906) macho; B, Cabeça e protórax, vista dorsal; C, Extremidade abdominal, vista dorsal; D, mesma, vista lateral; E, Valvas do ovipositor da fêmea, vista lateral. F, Complexo fálico com epífalo removido, vista lateral. G, Epífalo, vista dorsal.

proeminente acima dos ocelos, grosseiramente puncturada. Face, genas e occipício manchados de amarelo-claro. Mancha pós-ocular castanho-escura estendida até à porção superior do pronoto; margem inferior da genas e dos labro manchados de preto; fastígio do vértice subtriangular, mais largo do que longo com extremidade arredondada, levemente deprimido com sulco longitudinal mediano; espaço interocular estreito, olhos grandes e proeminentes, sem espaço entre o olho e a margem lateral da cabeça; occipício com puncturas (Fig. 3B), antenas filiformes, mais longas que a cabeça e pronoto juntos, compostas por 17 artículos.

Tórax. Carena mediana do pronoto não proeminente cortada por três sulcos transversais; ausência de carenas laterais borda posterior não angulada, com reentrância na região mediana; prozona com puncturas profundas, esparsas em relação às presentes na metazona, duas regiões da prozona sem puncturas, prozona maior que a metazona (Fig. 3B), borda posterior do pronoto com manchas pretas intercaladas, lóbulos laterais do pronoto manchados de amarelo, com uma faixa preta que percorre por toda extensão do lóbulo; tubérculo prosternal de base larga, com o ápice acuminado; espaço mesosternal subquadrado e lóbulo metasternais próximos; pleura, episterno metatorácico com manchas amareladas; pernas e ápice do abdome hirsutos; fêmur posterior amareloesverdeado, robusto, alcançando a extremidade abdome; tíbia posterior esverdeada com 7 espinhos na margem externa e interna; espinhos proximais menores em relação aos demais; tégminas delgadas, com ápices arredondado, ultrapassando a margem posterior do primeiro segmento abdominal, manchas tegminais alongadas.

Abdome. Tímpano presente; placa supranal subtriangular, mais longa do que larga, com sulco longitudinal mediano, as margens laterais levemente convergentes para o ápice, este, é amplamente arredondado (Fig. 3C), mais curta em relação aos cercos; placa subgenital curta e hirsuta com ápice arredondado; cercos longos, delgados, curvados para dentro na metade distal (Fig. 3D). Segmentos abdominais laterais 12 manchados de preto. Tarso posterior esverdeado.

Fêmea. Similar ao macho, porém maior (comprimento 19 $\mathrm{mm}$ ) e mais robusta. Olhos menos proeminentes; occipício amarelado com uma estreita faixa mediana amarelo-escura, com puncturas profundas e manchas escuras; tégminas alcançando a margem posterior do primeiro segmento abdominal; carena superior e inferior do fêmur posterior com manchas pretas intercaladas; valvas do ovipositor longas e delgadas, margem superior da valva dorsal serreada com ápice levemente curvado, dente apical externo da valva ventral levemente proeminente (Fig. 3E).

Material examinado. VENEZUELA. Vargas: Chichiriviche, x.1974 (A. Martinez), 1 macho (MLPA). Araguá: Araguá, 03-06.ii.1973 (H. R. \& E. H. Roberts, P. R. Anderson), 1 macho e 1 fêmea (MNRJ; M. A . Monné, det. 1979).

Notas sobre o tipo. Exame somente de fotografias; a fêmea de $S$. punctifrons depositada no NHMW, apresenta a antena direita quebrada na metade.

Comentários. O exame da fotografia do holótipo fêmea depositado no NHMW, e de exemplares comparados com o mesmo, permitiram a transferência desta espécie de Sitalces para o presente gênero.

L. punctifrons aproxima-se de L. dorsualis, da qual diferencia-se pela ausência de carena transversal na região mediana da placa supranal e a curvatura na metade distal da mesma. 

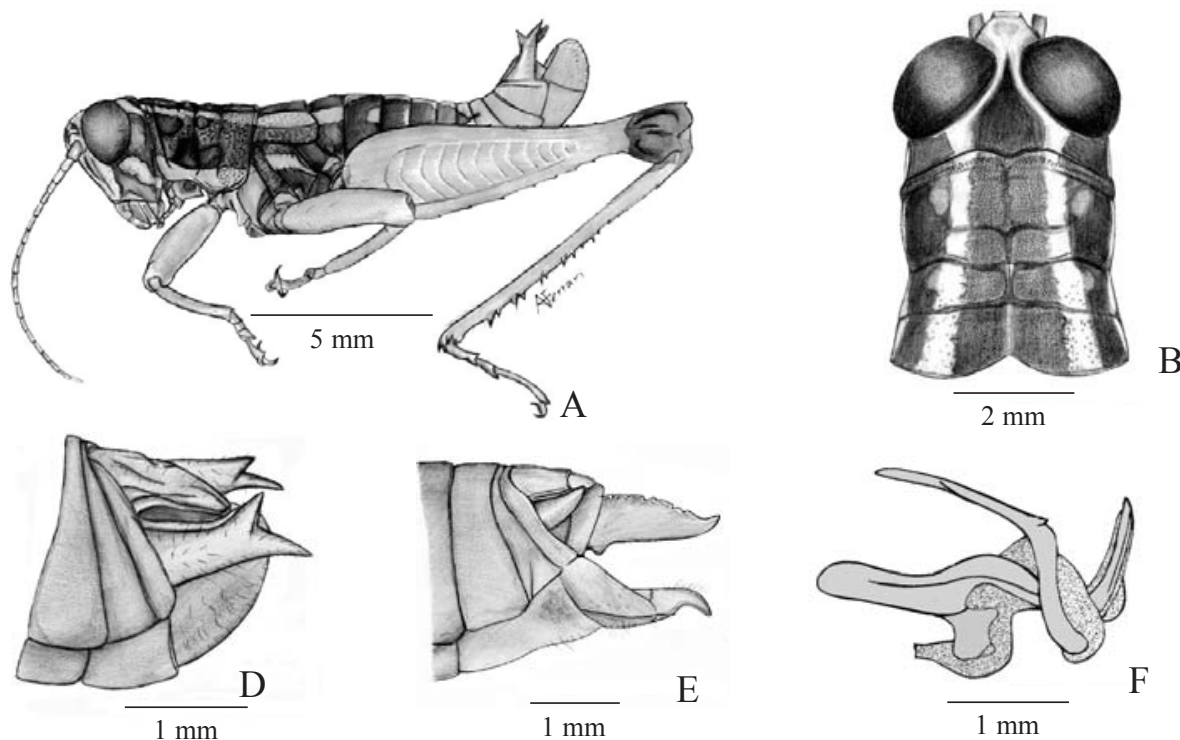

B
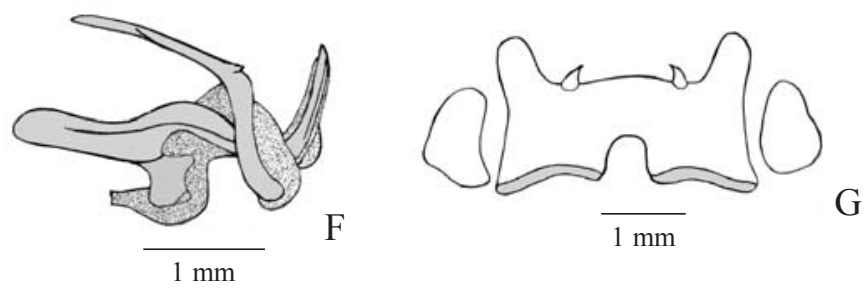

Figs. 6A, Eusitalces vittatus Bruner, 1911, macho; B, Cabeça e protórax, vista dorsal; C, Extremidade abdominal, vista dorsal; D, mesma, vista lateral. E, Valvas do ovipositor da fêmea, vista lateral. F, Complexo fálico com epífalo removido, vista lateral. G, Epífalo, vista dorsal.

O material pertencente ao MNRJ, não foi dissecado. A descrição da genitália foi baseada na observação externa.

Distribuição geográfica. Venezuela (Vargas e Araguá) (Fig. 9).

\section{Robustusacris gen. nov.}

Espécie-tipo: Sitalces balzapambae Rehn, 1913.

Diagnose. Micrópteros; forma do corpo robusta; espaço interocular amplo; olhos elípticos; occipício distintamente arqueado; pronoto levemente tectiforme; carena mediana do pronoto proeminente e borda posterior emarginada com uma reentrância na região mediana bem acentuada; fêmur posterior castanho-escuro com uma mancha escura na superfície dorsoexternal e área mediana bastante serreada; fêmur, tíbia e tarso posteriores avermelhados; placa supranal triangular com duas manchas de forma irregular na porção anterior da placa; cercos curtos e cônicos.

Etimologia. Do lat. robustus (alusivo à forma do corpo); Robustus + akris (=gafanhoto).

Robustusacris balzapambae (Rehn, 1913) comb. nov. (Figs. 4A, 4B, 4C, 4D, 4E, 4F)

Sitalces balzapambae Rehn, 1913: 105. Otte, 1978: 59 (locação do tipo). Sitalces rubripes Hebard, 1924: 190. Otte, 1978: 49 (locação do tipo). Syn. nov.

Macho(Fig. 4A). Tegumento extremamente rugosotuberculado. Forma do corpo robusta. Coloração do corpo castanho-escura. Medidas (em mm), 3 machos: C.c., 16,5 (16,2-18,2); C.p., 3,7 (3,2-3,9); C.f., 9,6 (9,4-10,8); C.t., 3,3 $(3,2-3,7)$.
Cabeça. De perfil, face subretilínea; cabeça tão larga quanto o pronoto; esta e a face manchadas de amarelo; genas castanho-claras. Occipício castanho-claro, arqueado e provido com um par de sulcos convergentes; costa frontal sulcada, não proeminente sobre o ocelo, superfície puncturada; fastígio do vértice triangular arredondado, distintamente mais largo do que longo, com leves sulcos na região mediana longitudinal, formando uma pequena depressão distinta entre os olhos, limitado por uma carena levemente proeminente (Fig. 4B); fóveola lateral puncturada; espaço interocular amplo, provido com um raso, mas distinto sulco; olhos elípticos, sem espaço entre o olho e a margem lateral da cabeça (Fig. 4B); antenas filiformes de coloração castanho-clara, distalmente mais escura, segmentos basais contornados de preto, mais longas do que a cabeça e pronoto juntos, composta por 17 artículos.

Tórax. Pronoto com dorso levemente tectiforme, carena mediana proeminente, cortada por três sulcos transversais profundos, prozona com duas regiões sem puncturas e maior em comprimento em relação a metazona; borda posterior do pronoto emarginada e não angulada, com uma reentrância acentuada na região mediana (Fig. 4B); lóbulos laterais do pronoto amarelados, com uma faixa mediana preta estendida até à pleura e a inserção do fêmur mediano; tubérculo prosternal abruptamente piramidal; espaço mesosternal subquadrado e lóbulos metatarsais distantes; fêmur posterior robusto, ultrapassando a extremidade do abdome, castanhoescuro com uma mancha escura na superfície dorso-external, carena e carênula superior interna levemente serreadas e área mediana interna muito serreada; margens ventrais dos lóbulos geniculares convexas; tíbia posterior avermelhada, com 8 espinhos na margem externa e 9 na interna, amarelados com metade apical preta; tarso posterior avermelhado com o terceiro artículo mais longo do que o primeiro; tégminas 

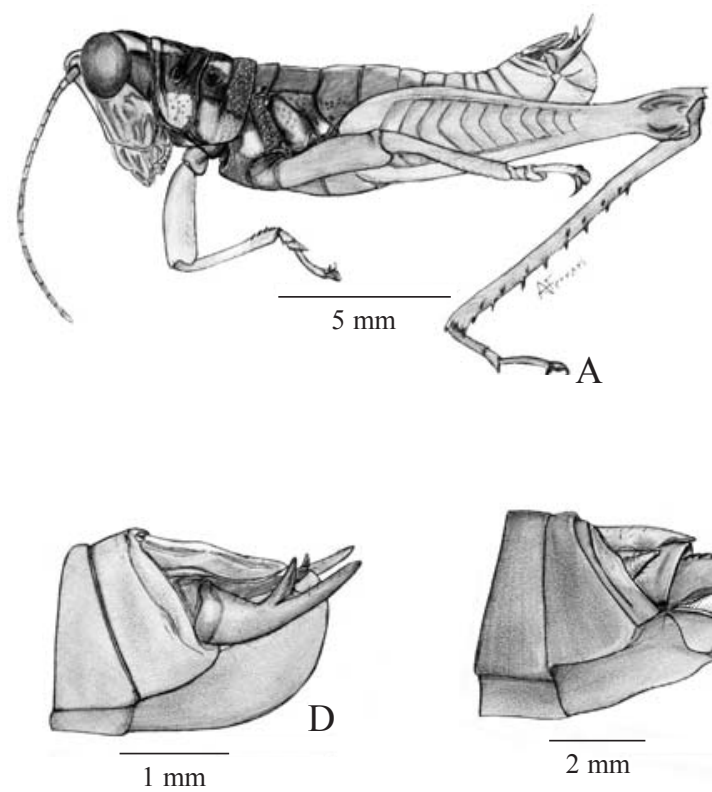

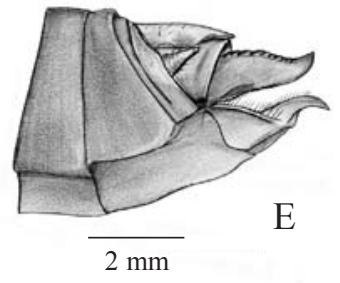

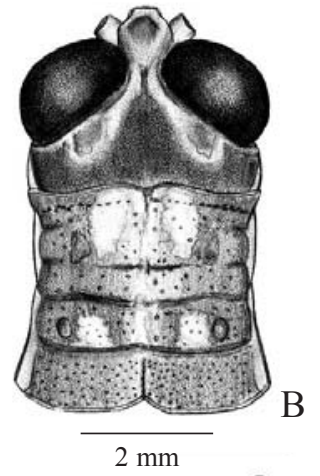

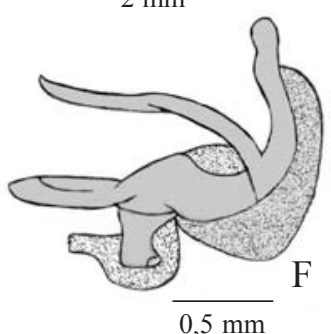

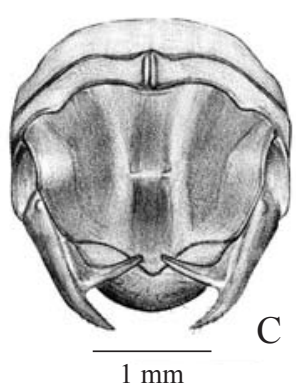

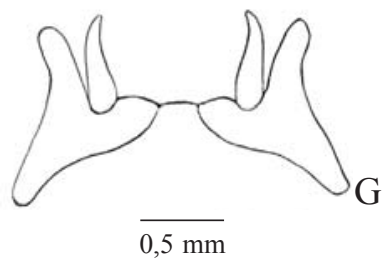

Figs. 7A, Parasitalces sexnotata Bruner, 1911, macho; B, Cabeça e protórax, vista dorsal; C, Extremidade abdominal, vista dorsal; D, mesma, vista lateral; E, Valvas do ovipositor da fêmea, vista lateral; F, Complexo fálico com epífalo removido, vista lateral; G, Epífalo, vista dorsal.

alcançando a margem anterior do primeiro segmento abdominal, ápice arredondado.

Abdome. Tímpano presente; abdome puncturado até o $5^{\circ}$ segmento; superfície ventral amarelo-escura; placa supranal triangular, mais larga do que longa, mais curta em relação aos cercos, com sulco longitudinal mediano proeminente, com duas manchas escuras de forma irregular na porção anterior da placa (Fig. 4C); placa subgenital com o ápice elevado sobre a margem dorsal da placa, arredondada quando vista do cima; cercos curtos, cônicos e hirsutos (Fig. 4D). Segmentos abdominais 2-6 com amplas manchas laterais pretas.

Complexo fálico. Apódema do cíngulo bem desenvolvida; arco do cíngulo dividido; escleritos endofálicos achatados dorso-ventralmente; gonóporo com expansão ventral digitiforme; bainha ectofálica do edeago ampla, muito desenvolvida, englobando totalmente o esclerito inferior do edeago; valvas superior e inferior do edeago curtas, com ápices divididos (Fig. 4E). Epífalo com ponte plana, âncoras convergentes e do mesmo tamanho que as projeções anteriores, estas desenvolvidas; lophis curvados, com protuberância mediana proeminente (Fig. 4F).

Fêmea (baseada na foto do alótipo). Similar ao macho, exceto por ser mais robusta e maior (comprimento 20,4 mm); cabeça com comprimento dorsal, da metade do tamanho do macho, olhos menos pronunciados; reentrância da borda posterior do pronoto menos conspícua do que o macho. Valvas do ovipositor, em vista lateral longas, margem superior da valva dorsal serreada, dente apical externo da valva ventral levemente proeminente.
Material examinado. EQUADOR. Pichincha: Santo Domingo, 11.xi.1956 (R.W. Portaman), 1 macho (ANSP; Idaho / C. S. Carbonell det.1970); Dos Puentes, alt. 17501 t., 9.i.1929 (W. J. Coxey) 1 macho (ANSP); Napo: Archidona, s.d (R. Haensch) 1 macho (MNMS; C. S. Carbonell det.1970).

Notas sobre os tipos. Exame somente de fotografias; o holótipo macho e alótipo fêmea de $S$. balzapambae, ambos depositados na ANSP, apresentam-se sem as antenas. Observou-se que o holótipo fêmea de $S$. rubripes, depositado na mesma Instituição, apresenta-se sem a antena esquerda.

Comentários. O exame de exemplares comparados com os tipos e das fotografias dos mesmos depositados na ANSP, confirmou a transferência desta espécie de Sitalces para o presente gênero.

Distribuição geográfica. Equador (Pinchincha, Napo, Bolívar e Chimborazo) (Fig. 9).

\section{Arimacris gen. nov.}

\section{Espécie-tipo: Sitalces trinitatis Bruner, 1906.}

Diagnose. Micrópteros; corpo de coloração castanhoescura, presença de uma ampla faixa dorsal amarelada que se estende desde o pronoto até o quarto segmento abdominal; cabeça amarelada, occipício com uma mancha subtriangular preta; antenas filiformes com 18 artículos; placa supranal subtriangular, com sulco longitudinal mediano profundo, com extremidades laterais largamente arredondadas, presença de duas protuberâncias na porção mediana da placa; borda posterior do último tergito com concavidade mediana limitada lateralmente por duas pequenas saliências; segmentos abdominais 2-5 com amplas manchas laterais pretas. 

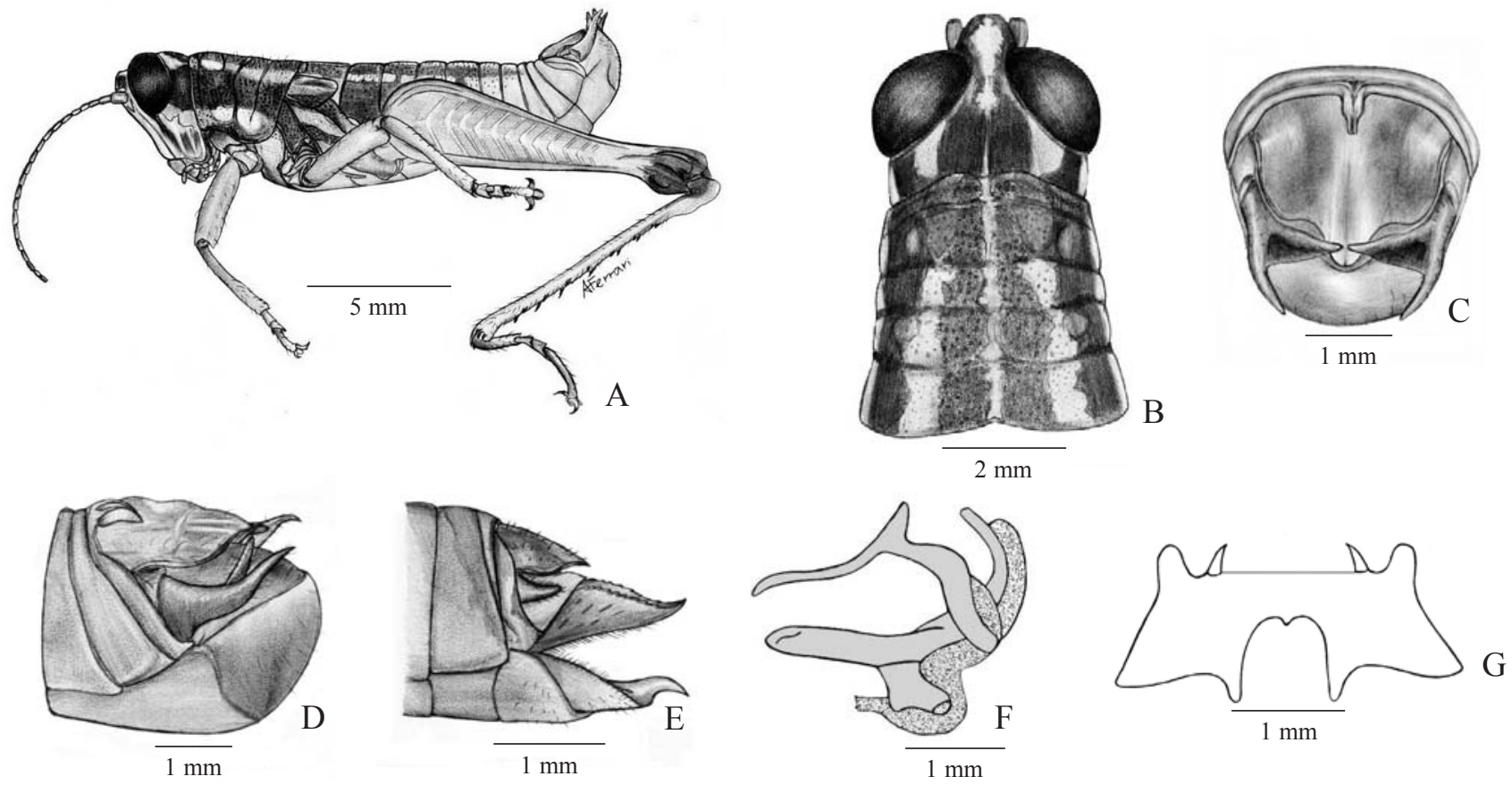

Figs. 8A, Parasitalces vulneratus (Bruner, 1919) macho; B, Cabeça e protórax, vista dorsal; C, Extremidade abdominal, vista dorsal; D, mesma, vista lateral; E, Valvas do ovipositor da fêmea, vista lateral; F, Complexo fálico com epífalo removido, vista lateral; G, Epífalo, vista dorsal.

Etimologia. O nome alusivo à região de ocorrência Arima + akris (= gafanhoto).

Arimacris trinitatis (Bruner, 1906) comb. nov. (Figs. 5A, 5B, 5C, 5D, 5E, 5F, 5G)

Sitalces trinitatis Bruner, 1906: 155. Kirby, 1910: 435; Bruner, 1910: 291 (chave), Roberts, 1937: 357; Dirsh, 1956: 277 (complexo fálico).

Macho (Fig. 5A). Tegumento rugoso. Coloração do corpo castanho-escuro, presença de uma ampla faixa dorsal amarelada que se estende desde o pronoto até o quarto segmento abdominal. Medidas (em $\mathrm{mm}$ ), respectivamente 3 machos e 3 fêmeas: C.c., 15,5 (15,1-15,5)/19,9 (18,8-20,6); C.p., $3,7(3,4-4,0) / 4,5(4,4-4,7)$; C.f., $10,0(9,5-10,1) / 12,2$ (10,6-13,7); C.t., 2,9 (2,9-3,0)/3,4 (3,2-3,7).

Cabeça. De perfil, face subretilínea; cabeça tão larga quanto o pronoto, amarelada, exceto de uma mancha subtriangular preta no occipício; lateral da cabeça, atrás dos olhos, abaixo das antenas, margem inferior das genas e labro manchados de preto; costa frontal sulcada e não proeminente, grosseiramente puncturada sobre os sulcos; fastígio do vértice subtriangular, mais largo do que longo com extremidade arredondada, levemente deprimido com sulco longitudinal mediano; fóveola lateral subquadrado; espaço interocular estreito, olhos grandes e proeminentes, espaço entre o olho e a margem lateral da cabeça ausente (Fig. 5B), antenas filiformes, mais longas que a cabeça e pronoto juntos, compostas por 18 artículos.
Tórax. Pronoto sem carenas laterais, puncturado, expandido sobre lóbulo superior; carena mediana não proeminente, cortada por três sulcos transversais; borda posterior do pronoto não angulada, com reentrância na região mediana (Fig. 5C), lóbulos laterais amarelados e fortemente sinuosos; prozona com duas regiões sem puncturas; metazona menor em tamanho em relação a prozona; tubérculo prosternal de base larga, com o ápice acuminado; espaço mesosternal subquadrado e lóbulos metasternais próximos; pleura e metade das pernas manchadas de amarelo; pernas e ápice do abdome hirsutos; fêmur posterior esverdeado, robusto, ultrapassando o ápice do abdome, lúnulas geniculares com manchas pretas; tíbia posterior esverdeada com 8 espinhos na margem interna e 7 na externa com ápices preto; tégminas com ápices arredondados, alcançando a margem posterior do primeiro segmento abdominal.

Abdome. Tímpano presente; segmentos abdominais 2-5 com amplas manchas laterais pretas; placa supranal subtriangular, mais larga do que longa, com sulco longitudinal mediano profundo, em relação aos cercos mais curta, com extremidades laterais largamente arredondadas, com duas protuberâncias na porção mediana da placa; borda posterior do último tergito com concavidade mediana limitada lateralmente por duas pequenas saliências (Fig. 5C); placa subgenital curta, com extremidade superior curvada e direcionada para dentro, ápice arredondado; pálio saliente; cercos longos, na porção distal voltados para dentro, quase alcançando a placa supranal (Fig. 5D). 
Complexo fálico. Apódema do cíngulo longa; escleritos endofálicos com ápodema aplainada dorso-ventralmente, placas laterais bem desenvolvidas, gonóporo com expansão ventral retangular; edeago com valvas superior a inferior longas e de mesmo tamanho com ápices divididos; bainha ectofálica do edeago ampla (Fig. 5F). Epífalo com ponte ampla e plana, âncoras bem desenvolvidas e convergentes do mesmo tamanho que as projeções anteriores, estas desenvolvidas, protuberância mediana entre os lophi em forma de M, são curvados e esclerotizados (Fig. 5G).

Fêmea. Similar ao macho, porém maior (comprimento 20 $\mathrm{mm}$ ) e mais robusta. Faixa dorsal amarelada menos conspícua que nos machos. Cabeça ferruginosa, com manchas escuras, exceto a porção inferior das genas mais pálida; palpos brancos. Ausência da mancha escura subtriangular no occipício. Olhos menos proeminentes; manchas abdominais pretas de coloração menos intensa do que as dos machos. Fêmur posterior castanho-amarelado com uma faixa oblíqua na face externa da metade basal, manchas esparsas de coloração parda ao longo da carena, face interna preta como também as lúnulas geniculares. Valvas do ovipositor curtas, margem superior da valva dorsal serreada com ápice levemente curvado e dente apical externo da valva ventral levemente proeminente com ápices curvados (Fig. 5E).

Material examinado. Lectótipo macho aqui designado: "Sitalces trinitatis Bruner Type" "Trinidad, O. E. Tryhane", of St. Anne's (Coll. L. Bruner) (UNSM). Paralectótipo fêmea aqui designado: mesmos dados do lectótipo. TRINIDAD \& TOBAGO. Saint George: Arima Valley, Simla, 26.ii.1966 (H. Grant \& V. Vickery), 1 macho (ANSP; comparado com o tipo); idem, 26.ii.1966 (V. Vickery), 1 macho (ANSP); idem, 21.ii.1966 (V. Vickery), 1 fêmea (ANSP; comparado com o tipo); idem, 22.ii.1966 (V. Vickery), 2 machos e 2 fêmeas (ANSP); idem, 23.ii.1966 (H. Grant \& V. Vickery), 1 macho (MNRJ; M. A. Monné, det. 1979), 1 fêmea (ANSP); idem, 30.iv.1964 (Ronderos), 1 macho (MLPA; Ronderos det. 1975); idem, Sangre Grande, 9.vi.1930 (G. Belmontes), 1 fêmea (MLPA); County of Caroni: Brasso, 14.v.1930 (G. Belmontes) 1 fêmea (MNRJ; M. A. Monné, det. 1979).

Notas sobre os tipos. Exame somente de fotografias; o lectótipo macho de $S$. trinitatis depositado na UNSM, apresenta-se sem o par de antenas e a extremidade abdominal está danificada.

Comentários. O exame da fotografia do lectótipo e dos exemplares comparados com os mesmos permitiram a identificação da espécie.

A espécie apresenta variações, sobretudo, na intensidade da coloração do corpo. Em alguns exemplares fêmeas, esta coloração é menos acentuada.

Distribuição geográfica. Trinidad \& Tobago (Fig. 9).

\section{Eusitalces Bruner, 1911}

Eusitalces Bruner, 1911: 142.

Espécie-tipo: Eusitalces vittatus Bruner,1911:142 por monotipia. Amédégnato, 1974: 202; Ferreira et al. 1980: 92.
Diagnose. Micrópteros; coloração castanho-escura para preto, com faixas amareladas; antenas filiformes com 18 artículos; prozona quase lisa, a metazona nitidamente puncturada; tíbia posterior com 6 espinhos na margem externa; placa supranal subtriangular, porção apical da placa com um profundo sulco longitudinal mediano, pontiagudo; cercos bifurcados.

Eusitalces vittatus Bruner, 1911

(Figs. 6A, 6B, 6C, 6D, 6E, 6F, 6G)

Eusitalces vittatus Bruner, 1911: 143. Descamps \& Amédégnato, 1970: 890 (Guiana Francesa); Ferreira et al. 1980: 91 (cromossomos); Mesa et al. 1983: 522 .

Sitalces apolinari Hebard, 1923: 269. Otte, 1978: 49 (locação do tipo). Syn. nov.

Eusitalces amazonicus Günther, 1940: 488. Syn. nov.

Macho (Fig. 6A). Tegumento puncturado. Coloração do corpo castanho-escura para preto, com faixas amareladas. Superfície ventral amarelada. Parte posterior da cabeça, genas, tórax e os cinco primeiros segmentos abdominais pretos, com duas faixas dorsos-laterais amareladas divergentes que iniciam entre os olhos, percorrem os lados do occipício, pronoto e estende-se até a metade interna das tégminas. Medidas em (mm), respectivamente: 6 machos/ 8 fêmeas: C.c., 13,5 (12,313,9)/ 17,0 (16,9-17,1); C.p., 3,1 (2,8-3,2)/ 4,1 (4,2-4,9); C.f., $9,1(8,7-9,4) / 10,8(10,6-11,7)$; C. t., $1,2(1,0-1,5) / 1,4(1,5-$ $1,7)$.

Cabeça. De perfil, face subretilínea; cabeça mais larga do que a margem anterior do pronoto; face e labro amarelados, occipício ascendendo por cima do plano do pronoto, costa frontal sulcada e proeminente sobre o ocelo; fastígio do vértice triangular, amarelado mais largo do que longo, provido com um sulco mediano longitudinal largo, o qual estreita-se posteriormente e continuando na extremidade da fronte do occipício; espaço interocular estreito; olhos grandes e proeminentes, subglobulares, espaço entre o olho e a margem lateral da cabeça ausente (Fig. 6B); antenas castanhoamarelados, mais longas que a cabeça e pronoto juntos, compostas por 18 artículos.

Tórax. Pronoto subcilíndrico com carena mediana longitudinal distinta, mas não proeminente, com uma estreita faixa médio-longitudinal amarelada estendida até o abdome, mais nitidamente demarcada na metazona, cortada por três sulcos profundos, ausência de carenas laterais, prozona quase lisa, a metazona, mais curta, nitidamente puncturada; borda posterior não angulada, com uma reentrância na região mediana (Fig. 6B); lóbulos laterais do pronoto amarelados; meso e metapleura com puncturas esparsas e manchadas de amarelo, segmentos abdominais com poucas puncturas na sua parte superior; tubérculo prosternal proeminente, com um ponto diminuto direcionado ligeiramente para fronte; espaço mesosternal subquadrado e lóbulos metasternais próximos; fêmur posterior robusto, ferruginoso, tornando-se esverdeado apicalmente, ultrapassando a extremidade do abdome, carena 


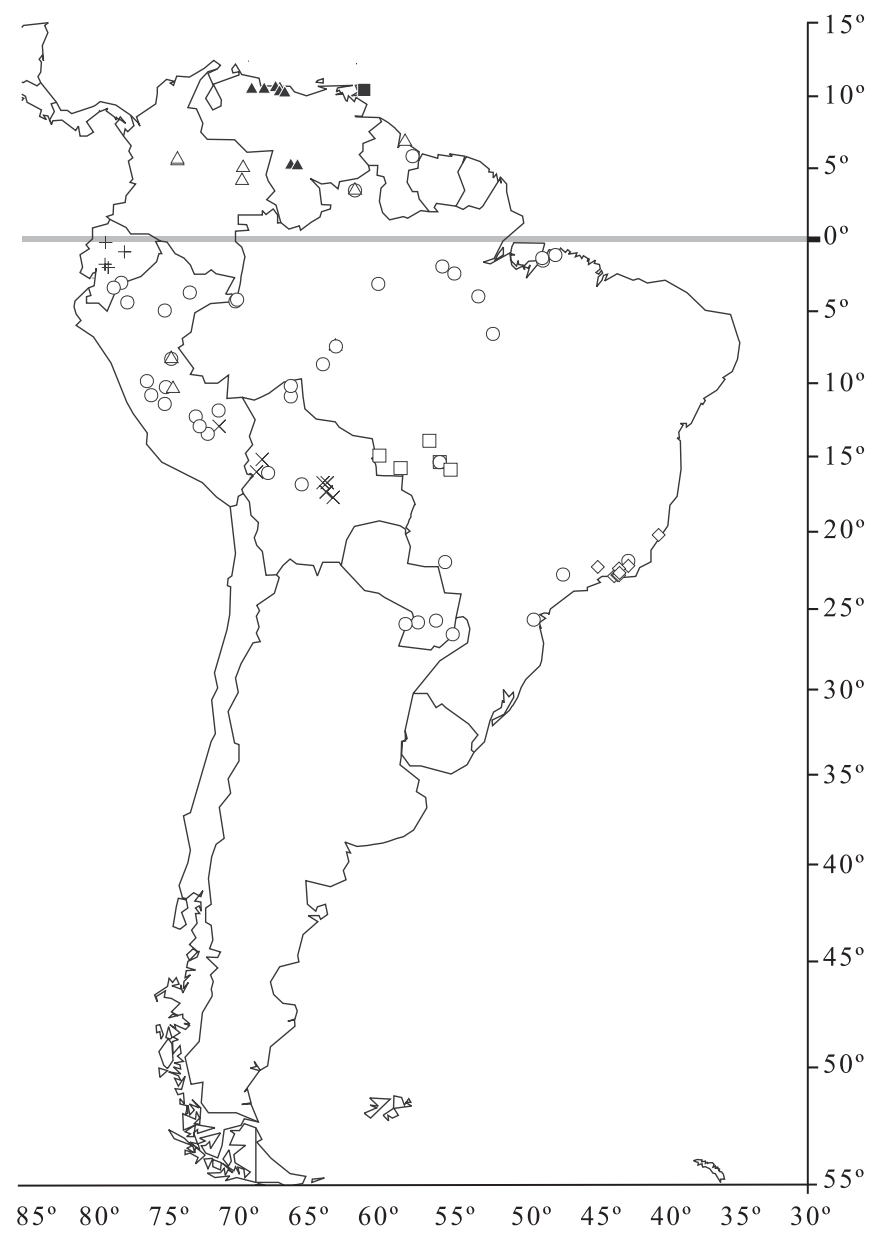

Fig. 9. Distribuição geográfica das espécies: $\diamond S$. volxemi; $\bigcirc$ L. dorsualis; $\Delta$ L. punctifrons; + R. balzapambae; $\square$ A. trinitatis; $\triangle$ E. vittatus; $\square P$. sexnotata; $\times$ P. vulneratus

superior com fraca serreações, na inferior são mais proeminentes; lóbulos geniculares pretos com margens ventrais fortemente convexa; tíbia posterior esverdeada, hirsuta, com 6 espinhos com ápices pretos na margem externa e 7 na interna; tarso posterior esverdeado, hirsuto, com o artículo terminal igual ou um pouco maior do que o primeiro e o segundo artículos associados, arólio grande; tégminas de coloração preta, curtas, ovais, alcançando apenas até a metade do metanoto.

Abdome. Tímpano inconspícuo; faixa mediana do abdome longitudinal e amarelada, estendida até o $5^{\circ}$ segmento; placa supranal subtriangular, mais longa do que larga, porção apical da placa com um profundo sulco longitudinal mediano, pontiagudo percorrendo a metade da mesma, e na porção distal, com um sulco transversal, onde a placa é suavemente voltada para baixo, ápice arredondado; em relação aos cercos mais curta (Fig. 6C); placa subgenital curta e hirsuta; cercos bifurcados, um pouco mais longos do que placa supranal, curvados para dentro na metade apical, haste externa do cerco mais longa e delgada do que a interna (Fig. 6D).
Complexo fálico. Cíngulo com ápodema longa, escleritos endofálicos com apódema aplainada dorso-ventralmente, placas laterais desenvolvidas, gonóporo com expansão ventral retangular; edeago curto com valvas superior e inferior de tamanho igual, com ápices divididos; bainha ectofálica do edeago estreita (Fig. 6F). Epífalo com ponte levemente convexa; âncoras convergentes, mais curtas que as projeções anteriores, estas muito desenvolvidas; lophi não curvados; escleritos ovais bem grandes e desenvolvidos (Fig. 6G).

Fêmea. Similar ao macho, porém maior (comprimento 17 $\mathrm{mm}$ ) e mais robusta. Tégminas alcançando a borda posterior do metanoto. Valvas do ovipositor longas e robustas, valva dorsal com margem externa serreada, o ápice dorsal moderadamente curvado, dente apical externo da valva ventral proeminente e curvado (Fig. 6E). Caracteres cromáticos coincidentes com os descritos para o macho, exceto por apresentar uma estreita listra mediana longitudinal amarelada no occipício. Mancha preta entre os olhos interrompida por amarelo.

Material examinado. COLÔMBIA. Bogotá: Vichada, 20.i.1970 (N. D. Jago), 1 macho (MLPA; S. apolinari). BRASIL. Roraima: Ilha de Maracá, vi. 1981 (sem coletor)/ Museum Paris Bresil. M. Descamps rec.), 2 machos (INPA; 0022061 e 0022382/ M. Descamps det. 1981); s. 1., s.d. (Vieira, M. F. det. 1997), 1 fêmea (INPA; 0022606). Amazonas: Humaitá, 8.x.1975 (A. Mesa), 3 machos e 3 fêmeas (FCUR; E. amazonicus); Rondônia: Cachoeira de Samuel, Jamari, ii.1944 (Parko), 1 macho e 1 fêmea (MNRJ; E. amazonicus/ C. S. Carbonell det. 2001). PERU. Loreto: San Jorge Pucallpa, 19.ii.1962 (A. Mesa), 1 macho e 1 fêmea (FCUR; E. vittatus/C. S. Carbonell det. 2001); Pasco: Puerto Yessup, ii.1930 (M. A. Carriker), 1 macho e 1 fêmea (ANSP; parátipo/ S. apolinari); Cuzco: Paucartambo, Pilcopata, vi. 1976 (C.S.Carbonell \& M. Descamps), 1 fêmea (FCUR; comparado com o tipo/ E. amazonicus).

Notas sobre os tipos. Parátipo de S. apolinari da ANSP em ótimo estado, apenas sem o par de antenas. Através do exame das fotografias do holótipo macho de E. vittatus, depositado na UNSM, observou-se à ausência da antena esquerda; e o holótipo fêmea de E. amazonicus depositado no SMTD, apresenta-se sem a antena direita.

Comentários. O exame dos exemplares comparados com os tipos e por fotografias dos mesmos, permitiram que as espécies S. apolinari Hebard, 1923 e E. amazonicus Günther, 1940, fossem consideradas sinônimos de E. vittatus Bruner, 1911.

As espécies provenientes da região norte do Brasil, Amazonas (Humaitá), apresentam os fêmures anteriores, medianos e posteriores de coloração avermelhada.

Distribuição geográfica. Guiana (Demerara); Brasil (Amazonas, Roraima, Rondônia); Peru (Loreto, Pasco e Cuzco) e Colômbia (Bogotá) (Fig. 9).

\section{Parasitalces Bruner, 1911}

Parasitalces Bruner, 1911: 124.

Espécie-tipo: Parasitalces sexnotata Bruner,1911 por monotipia. 
Diagnose. Micrópteros ou ápteros; coloração variando do castanho-clara ao esverdeada, com manchas avermelhadas ou alaranjadas na prozona; cabeça tão larga quanto o pronoto; antenas filiformes com 19 artículos; tíbia posterior com 8 espinhos; placa supranal subretangular, mais larga do que longa; borda posterior do último tergito com fúrcula; cercos longos e bifurcados.

\section{Chave para as espécies de Parasitalces}

1. Áptero. Prozona com 2 pares de manchas alaranjadas. Borda posterior do último tergito com uma fúrcula pequena; cercos com hastes de espessuras iguais e bifurcação arredondada. Valvas do ovipositor delgadas P. sexnotata Bruner

Micróptero. Prozona com 1 par de manchas avermelhadas. Borda posterior do último tergito com uma fúrcula grande; cercos com hastes de espessuras desiguais e bifurcação angulada. Valvas do ovipositor robustas ..... . P. vulneratus (Bruner)

Parasitalces sexnotata Bruner, 1911

(Figs. 7A, 7B, 7C, 7D, 7E, 7F, 7G)

Parasitalces sexnotata Bruner, 1911: 125.

Macho(Fig. 7A). Áptero. Tegumento liso Coloração castanho-esverdeada mais clara médio-dorsalmente e posteriormente. Cabeça e pronoto dorsalmente com três pares de manchas, um par na cabeça em cada lado do occipício e dois pares na prozona e nas margens laterais do disco do pronoto de coloração alaranjada bastante conspícua. Medidas (em mm), respectivamente: 3 machos/ 5 fêmeas: C.c., 13,5 (14,0-14,2)/ 20,5 (19,3-21,4); C.p., 2,3 (2,3-2,6)/ 4,4(3,2-4,1); C. f., $9,0(8,5-9,0) / 11,7(11,6-12,2)$.

Cabeça. De perfil, face fortemente oblíqua; cabeça tão larga quanto a margem anterior do pronoto, occipício liso e razoavelmente longo; costa frontal plana e não proeminente; fastígio do vértice subtriangular, mais largo do que longo (Fig. 7B), com margem ântero-lateral carenada; espaço interocular amplo, olhos grandes e proeminentes, espaço entre o olho e a margem lateral da cabeça ausente; antenas filiformes, amareladas, infuscadas apicalmente, com 19 artículos, um pouco mais longas do que o comprimento da cabeça e pronoto juntos.

Tórax. Pronoto hirsuto, carena mediana distinta, mas não proeminente, cortada por três sulcos distintos, ausência de carenas laterais; borda posterior do pronoto, com uma reentrância na região mediana; prozona com puncturas mais esparsas do que as da metazona, esta mais puncturada, e menor que a metazona (Fig. 7B); pleura puncturada; tubérculo prosternal curto, pequeno, locado na base, com ápice acuminado; espaço mesosternal transversal e lóbulos metasternais próximos; pernas castanho-esverdeadas; fêmur posterior com carena lisa, alcançando a extremidade do abdome; lúnulas geniculares e margens inferiores do fêmur posterior de coloração ferruginosa; presença de uma mancha avermelhada na pleura e na inserção do fêmur posterior bastante distinta; tíbia posterior esverdeada, hirsuta, com margem externa e interna com 8 espinhos; os esporões maiores no lado interno; tarsos de coloração castanho; faixa mediana longitudinal amarela, estendida do meso e metatórax até o $6^{\circ}$ segmento abdominal e faixas laterais torácicas escuras.

Abdome. Tímpano pequeno e oval; placa supranal subretangular, mais larga do que longa, em relação aos cercos mais curta; margem anterior sinuosa, as laterais elevadas e suavemente convergentes posteriormente, região mediana profundamente sulcada, abruptamente mais baixa da metade para o ápice; borda posterior do último tergito com uma pequena fúrcula (Fig. 7C); placa subgenital curta, hirsuta; cercos bifurcados, robustos, com as hastes do mesmo tamanho e bifurcação arredondada (Fig. 7D).

Complexo fálico. Cíngulo com apódema longa; escleritos endofálicos com ápodema aplainada dorso-ventralmente, placas laterais bem desenvolvidas; gonóporo com expansão ventral retangular; edeago longo com as valvas superior e inferior de mesmo tamanho, com ápices divididos; bainha ectofálica do edeago ampla e desenvolvida (Fig. 7F). Epífalo com ponte plana, âncoras convergentes, longas e bem desenvolvidas, estas apresentam o mesmo tamanho que as projeções anteriores; projeções anteriores desenvolvidas e as posteriores divergentes; lophi não curvados, com protuberância mediana (Fig. $7 \mathrm{G}$ ).

Fêmea. Similar ao macho, porém, maior e mais robusta (comprimento $21 \mathrm{~mm}$ ) com olhos menos proeminentes. Valvas do ovipositor longas e delgadas, margem superior da valva dorsal serreada, dente apical externo da valva ventral levemente proeminente (Fig. 7E). Meso e metatórax, segmentos 1-4 abdominais com manchas amareladas na porção dorso-lateral.

Material examinado. BRASIL. Mato Grosso: Chapada dos Guimarães, iv. s.ano (sem coletor), 1 macho (ANSP; alótipo); idem, iii.1979 (Roppa e Silva), 1 macho e 1 fêmea (MNRJ; comparado com o tipo AC1485); Diamantino, BR 163, Km 200, v. 1980 (B. Silva), 1 fêmea (MNRJ; AC1482); Cáceres, Porto Esperidião, ix.1984 (Magno e Alvarenga), 1 macho (MNRJ; AC1483); Ruta 364, Córrego Boa Vista, 23.i.1972 (C. S. Carbonell; R. A. Ronderos), 2 fêmeas (FCUR); Córrego Boa Vista, = 24.i.1972 (Ronderos; C. S. Carbonell) 1 macho (MLPA); Jaciara, 24.i.1972 (C. S. Carbonell; R. A. Ronderos) 1 fêmea (FCUR).

Notas sobre o tipo. Alótipo macho examinado em mal estado, faltando uma das pernas tanto anteriores como posteriores; abdome está danificado. Pelo exame da fotografia do holótipo fêmea depositado na ANSP, observou-se a falta da antena direita.

Distribuição geográfica. Brasil (Mato Grosso) (Fig. 9). 
Parasitalces vulneratus (Bruner, 1919) comb. nov. (Figs. 8A, 8B, 8C, 8D, 8E, 8F, 8G)

Eusitalces vulneratus Bruner, 1919: 79. Ferreira et al. 1980: 91 (cromossomos); Mesa et al. 1983: 522 (cromossomos). Eusitalces rubripes Günther, 1940: 489. Syn. nov.

Macho(Fig. 8A). Tegumento puncturado até $1^{\circ}$ segmento abdominal. Coloração do corpo castanho-escura, quase preta, com faixas amareladas. Superfície ventral mais clara. Medidas (em mm), respectivamente 10 machos/10 fêmeas: C.c., 17,6 (16,7-17,1)/ 19,8 (19,5-21,9); C.p., 3,7 (3,2-3,5)/ 4,2 (4,04,6); C. f., $10,8(9,7-10,3) / 11,3(11,8-13,5)$; C.t., $1,7(1,4-$ $2,0) / 1,8(1,5-1,8)$.

Cabeça. De perfil, face subretilínea; cabeça tão larga quanto a margem anterior do pronoto; cabeça, fronte, metade anterior e margens inferiores da gena, disco fastigial e junções basais das antenas de coloração amarelada; occipício curto, arredondado, porções laterais e mediana com uma listra estreita amarela; o restante da cabeça preto; costa frontal plana e não proeminente, puncturada entre as antenas; fastígio do vértice subtriangular, deprimido, ligeiramente, mais largo do que longo com extremidade retilínea, as margens laterais grosseiramente carenadas; espaço interocular amplo, olhos grandes e proeminentes, espaço entre o olho e a margem lateral da cabeça ausente (Fig. 8B); antenas filiformes, de coloração castanho-ferruginosa, mais longas que a cabeça e pronoto juntos, compostas por 19 artículos.

Tórax. Pronoto grosseiramente puncturado, ornado com duas faixas dorsos-laterais amareladas e uma dorsal-mediana estreita da mesma cor, estendida até o $7^{\circ}$ segmento abdominal; carena mediana distinta, mas não proeminente cortada por três sulcos transversais profundos; ausência de carenas laterais, borda posterior do pronoto não angulada, com uma reentrância na região mediana (Fig. 8B); prozona maior que a metazona; prozona e lóbulos laterais conspícuamente marcados com grande mácula vermelho-alaranjada; na prozona e nos segmentos abdominais anteriores com puncturas de pouco relevo e esparsamente distribuídas; pleura amarelada; tubérculo prosternal delgado, acuminado; espaço mesosternal subquadrado e lóbulos metasternais próximos; laterais do meso e metatórax de coloração preta; fêmur posterior esverdeado, robusto na base, uniformemente afilado apicalmente, alcançando a extremidade do abdome; lóbulo geniculares pretos e acuminados; tíbia posterior de coloração verde-escura, hirsuta, espinhos com ápices pretos, margem externa com 8 espinhos, dos quais os proximais muito pequenos; tégminas pretas, com uma faixa mediana dorsal amarela, ultrapassando a margem posterior do primeiro segmento abdominal.

Abdome. Tímpano inconspícuo; placa supranal grande, subretangular, mais larga do que longa, margens laterais próximas da base elevadas, sinuosas, na porção mediana profundamente elevada longitudinalmente formando depressões laterais largas, em relação aos cercos mais curta (Fig. 8C); placa subgenital curta, com ápice voltado para cima, arredondado (Fig. 8D); abdome levemente clavado apicalmente; cercos bifurcados, longos, pontiagudos e robustos na base, haste interna mais grossa e curvada para dentro, seus ápices quase se tocando, a haste externa mais delgada, bifurcação angulada; borda posterior do último tergito com uma grande fúrcula (Fig. 8D). Segmentos abdominais basais e dorsos-laterais de coloração preta.

Complexo fálico. Apódema do cíngulo longa; escleritos endofálicos com ápodema aplainada dorso-ventralmente, placas laterais bem desenvolvidas, bainha ectofálica ampla; gonóporo com expansão ventral retangular; edeago longo com valvas superior a inferior de mesmo tamanho, com ápices não divididos (Fig. 8F). Epífalo com ponte plana, âncoras afiladas, convergentes, mesmo tamanho que as projeções anteriores, estas desenvolvidas; lophi não curvados com protuberância mediana bastante desenvolvida, porções internas mais pronunciadas (Fig. 8G).

Fêmea. Similar ao macho, porém maior (comprimento 21,9 $\mathrm{mm}$ ) e mais robusta. Tégminas alcançando a margem posterior do primeiro segmento abdominal. Valvas do ovipositor longas e robustas, a margem superior da valva dorsal serreada, dente apical externo da valva ventral levemente proeminente (Fig. 8E). Caracteres cromáticos coincidentes com os descritos para o macho.

Material examinado. PERU. Cuzco: Atalaya, confluência dos rios Alto Madre de Dios y Carbón, vi. 1976 (C. S. Carbonell; M. Descamps) 2 machos e 4 fêmeas (FCUR; E. rubripes/ C. S. Carbonell det.1966); Paucartambo, Pilcopata, vi.1976 (C. S. Carbonell; M. Descamps) 1 macho e 1 fêmea (FCUR; E. rubripes). BOLÍVIA. La Paz: Mapiri, s.d (sem coletor), 2 machos (comparados com o tipo) e 2 fêmeas (NHRS; E. rubripes/ C. S. Carbonell, det. 1966); Província del Sara, s.d (Steimbach), 1 fêmea (MLPA; Ronderos det. 1975); Santa Cruz: Naranjales, 18.iv.1962 (A. Mesa), 12 machos (1 macho comparado com o tipo) e 10 fêmeas (FCUR; C.S. Carbonell det. 1966); idem, 1 macho (MNRJ) e 1 fêmea (MNRJ; C.S. Carbonell det.1978); Buena Vista, s.d. (Steimbach), 1 macho (MLPA; Ronderos det. 1975); Ichilo, ii. 1950 (A. Martinez), 3 machos (MZSP).

Notas sobre os tipos. Exame somente de fotografias; lectótipo macho e paralectótipo fêmea de E. vulneratus, ambos depositados na ANSP encontram-se em bom estado. O holótipo de E. rubripes depositado em SMTD, encontra-se sem as antenas.

Comentários. Através do exame das fotografias do material tipo e dos exemplares comparados com os mesmos, foi possível propor a sinonímia de E. rubripes com a presente espécie.

$P$. vulneratus aproxima-se de P. sexnotata, diferindo, basicamente pela coloração, número de manchas presente na prozona, tamanho da fúrcula, forma do epífalo e ausência de asas.

Os exemplares identificados como E. rubripes Günther, 1940, provenientes da Bolívia (Mapiri), apresentam o labro com manchas pretas, ausência da mácula vermelha no pronoto, fêmures anteriores e medianos avermelhados e placa supranal 
avermelhada até a metade. Abdome preto até o $7^{\circ}$ segmento, com exceção dos cercos e da borda posterior da placa supranal que são pretos.

Os exemplares provenientes do Peru, Departamento de Cuzco, Província de Paucartambo, Pilcopata, apresentam as duas listras pronotais amareladas mais estreitas e estas não atingem até o $7^{\circ}$ segmento abdominal, apenas a medianadorsal. Lóbulos geniculares ferruginosos com lúnula avermelhada.

Distribuição geográfica. Peru (Cuzco) e Bolívia (La Paz, Santa Cruz) (Fig. 9).

Agradecimentos. Ao Prof. Carlos Salvador Carbonell pela inestimável contribuição a este trabalho, pelo empréstimo do material e fotografias dos tipos. Ao Dr. Miguel A. Monné (MNRJ); Prof ${ }^{a}$. Maria Marta Cigliano (MLPA); José Albertino Rafael (INPA) pelo empréstimo do material. Ao Biólogo Augusto Ferrari pela execução das ilustrações e a Eleandro Sidney Moyses pelo auxílio na elaboração do mapa de distribuição. Ao CNPq pela concessão da bolsa de estudo ao primeiro autor (Proc. 140687/2001-7).

\section{REFERÊNCIAS}

Amédégnato, C. 1974. Les genres d'acridiens néotropicaux, leur classification par familles, sous-familles et tribus. Acrida 3: 193-204.

Amédégnato, C. \& M. Descamps, 1980. Evolution des populations d'orthoptéres d'Amazonie du nord-ouest dans les cultures et les formations secondaires d'origine anthropique. Acrida 9: 1-33.

Bruner, L. 1906. Report on the Orthoptera of Trinidad, West Indies. Journal of the New York Entomological Society 14: 135-165.

Bruner, L. 1908. Acrididae. Biologia Centrali Americana 2: 249-342.

Bruner, L. 1910. On some Acridoidea from Puerto Bertoni, Paraguay. Entomological News 21: 301-307.

Bruner, L. 1911. I. South American Acridoidea. Annals of the Carnegie Museum 8: 5-147.

Bruner, L. 1919. I. Saltatorial Orthoptera from South America and the Isle of Pines. Annals of the Carnegie Museum 13: 5-91.

Brunner, V. W. K. 1893. Révision du système des Orthoptères et description des espèces rapportés par M. Leonardo Fea de Birmanie. Annali del Museo Civico di Storia Naturale di Genova, ser. 2, 13: 5-230.

Carbonell, C. S. \& M. Descamps, 1978. Revue des Ommatolampae (Acridoidea, Ommatolampinae). Annales de la Société Entomologique de France (N.S.) 14: 1-35.

Cigliano, M. M. \& C. E. Lange. 1988. Orthoptera. In: Biodiversidade de Artrópodos Argentinos.1 ed. Laplata, Argentina. Ediciones SUR. 599 p.

Descamps, M. 1976. Le peuplement acridien d'un pèrimétre d'Amazonie colombienne. Annales de la Société Entomologique de France (N.S.) 12: $291-318$

Descamps, M. 1979. Missions entomologiques en Guyane et au Brésil. Troisiéme note: Orthoptera Acridomorpha. Annales de la Société Entomologique de France (N.S.) 15: 311-317.

Descamps, M. \& C. Amédégnato. 1970. Acridomorpha (Orthoptera) récoltés en Guyane Française par la mission du Muséum National d'Histoire Naturelle. Annales de la Société Entomologique de France (N.S.) 6: 861-897.

Dirsh, V. M. 1956. The phallic complex in Acridoidea (Orthoptera) in relation to taxonomy. Transactions of the Royal Entomological
Society of London 108: 223-356, 66 pl.

Ferreira, A.; A. Mesa \& C. S. Carbonell, 1980. The chromosomes of neotropical short-horned grasshoppers of the tribe Abracrini (Orthoptera, Acridoidea, Acrididae, Ommatolampinae). Naturalia 5: 89-95.

Giglio-tos, E. 1898. Viaggio del Dr. Enrico Festa nella Republica dell' Ecuador e regioni vicine. VI, Ortotteri. Bollettino dei Musei di Zoologia ed Anatomia Comparata della R. Universitá di Torino 13: $1-108$.

Grossbeck, J. A. 1912. Types of insects, except Lepidoptera and Formicidae, in the American Museum of Natural History additional to those previously listed. Bulletin of the American Museum of Natural History 31: 353-379.

Günther, K. 1940. Ueber die Verbreitung eininger Insekten im Gebiete des Amazonenstromes und die Frage eines columbischen Faunendistriktes in der brasilianischen Subregion. Archiv für Naturgeschichte, Leipzig, (NF) 9: 450-500.

Hebard, M. 1923. Studies in the Dermaptera and Orthoptera of Colombia. Third Paper,Orthopterous family Acrididae. Transactions of the American Entomological Society 49: 165-313, pl. 10-17.

Hebard, M. 1924. Studies in the Dermaptera and Orthoptera of Ecuador. Proceedings of the Academy of Natural Sciences of Philadelphia 76: 109-248, pl. 5-10.

Kirby, W. F. 1910. A synonymic catalogue of Orthoptera. Vol. 3. Orthoptera, Saltatoria. Part. 2. (Locustidae vel Acrididae). British Museum, London, 674 pp.

Liebermann, J. 1955. Primeira relação sistemática dos acridóideos do Brasil. Memórias do Instituto Oswaldo Cruz 53: 329-344.

Mesa, A.; A. Ferreira \& C. S. Carbonell. 1983. Cariología de los acridoideos neotropicales: estado actual de su conocimiento y nuevas contribuciones. Annales de la Société Entomologique de France (N.S.) 18: 507-526.

Otte, D. 1978. The primary types of Orthoptera (Saltatoria, Mantodea, Phasmatodea and Blattodea) at the Academy of Natural Sciences of Philadelphia. Proceedings of the Academy of Natural Sciences of Philadelphia 130: $26-87$.

Papavero, N. \& U. R. Martins. 1994. Itens de publicação Taxonômica. 69105 p. In: Papavero, N. Fundamentos práticos de taxonomia Zoológica. 2. ed. rev. e ampl. São Paulo, Editora da Universidade Estadual Paulista, 285 p.

Passerin d'entreves, P. 1981. Cataloghi. IV - Collezioni ortotterologiche del Museo di Zoologia dell' Universitá di Torino. Museo Regionale di Scienze Naturali, Torino, 127 pp.

Rehn, J. A. G. 1913. Descriptions and records of South American Orthoptera, with the description of a new subspecies from Clarion Island. Proceedings of the Academy of Natural Sciences of Philadelphia 63: $82-113$.

Rehn, J. A. G. 1916. The Stanford Expedition to Brazill, 1911. Dermaptera and Orthoptera I. Transactions of the American Entomological Society 42: 215-308, pl. 14, 15.

Rehn, J. A. G. 1917. On Orthoptera from the vicinity of Rio de Janeiro, Brazil. Transactions of the American Entomological Society 43: 335363.

Rehn, J. A. G. 1918. On a collection of Orthoptera from the State of Pará, Brazil. Proceedings of the Academy of Natural Sciences of Philadelphia 70: 144-236, 2 pl.

Roberts, H. R. 1937. Studies on the family Acrididae (Orthoptera) of Venezuela. Proceedings of the Academy of Natural Sciences of Philadelphia 89: 343-368, pl. 13-14.

Sjöstedt, Y. 1933. Orthopterentypen im Naturhistorischen Reichsmuseum zu Stockholm. 2, Acrididae. Arkiv för Zoologi 24: 1-89, 20 pl.

Stål, C. 1878. Systema acridiodeorum. Essai d'une systematisation des acridoidées. Bihang till Kongliga Svenska Vetenskaps-akademiens Handlingar 5: 1-100. 